\title{
Interconnectedness, Systemic Crises and Recessions
}

Marco A. Espinosa-Vega and Steven Russell 


\title{
IMF Working Paper
}

Institute for Capacity Development

\section{Interconnectedness, Systemic Crises and Recessions}

\section{Prepared by Marco A. Espinosa-Vega and Steven Russell ${ }^{1}$}

Authorized for distribution by Jorge Roldós

February 2015

\begin{abstract}
This Working Paper should not be reported as representing the views of the IMF. The views expressed in this Working Paper are those of the author(s) and do not necessarily represent those of the IMF or IMF policy. Working Papers describe research in progress by the author(s) and are published to elicit comments and to further debate.
\end{abstract}

\begin{abstract}
This relatively simple model attempts to capture and integrate four widely held views about financial crises. [1] Interconnectedness among financial institutions (banks) can play a major role in precipitating systemic financial crises. [2] Lack of information about the quality of bank portfolios also plays a role in precipitating systemic crises. [3] Financial crises, particularly systemic ones, are often followed by severe, lengthy recessions. [4] Loss of confidence in the financial system is partly responsible for the length and severity of these recessions. In the model, banks make decisions about initiating and liquidating risky loans. Interconnectedness among their asset portfolios can obscure information about these portfolios, causing them to make inefficient decisions about liquidation, and about retention of the managers who assess credit risk. These decisions can increase the depth of recessions, and they can produce systemic financial crises. They can also reduce the effectiveness of future bank risk assessment, increasing the probability of lengthy, severe recessions. The government, acting in the interest of current and future depositors, may wish to increase the transparency of bank portfolios by limiting interconnectedness. The optimal degree of regulation, which may depend on depositors' degree of risk aversion, may not eliminate financial crises.
\end{abstract}

JEL Classification Numbers: G11, G12, G20, G33

Keywords: financial crisis, systemic risk, interconnectedness, recession

Author's E-Mail Address: mespinosa@imf.org

\footnotetext{
${ }^{1}$ We thank Jorge Roldos, Jean-Charles Rochet and the participants in our session at the Midwest Economic Theory meetings in Spring 2014 for helpful comments. Russell has conducted much of his part of this research as a visiting scholar at the Institute for Capacity Development. The authors are also grateful to Sophia Chen, Gaston Gelos, Brenda Gonzalez-Hermosillo, and Laura Valderrama for their comments.
} 


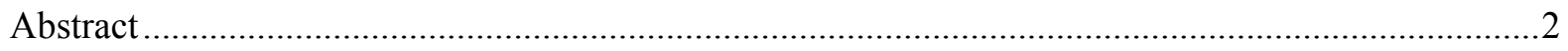

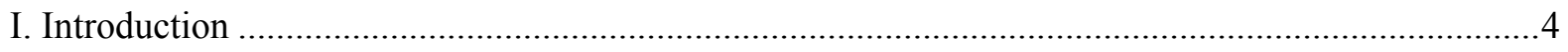

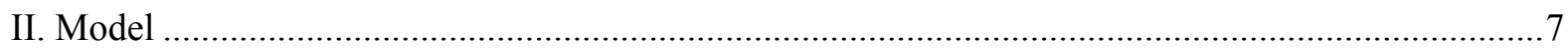

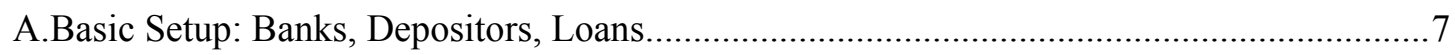

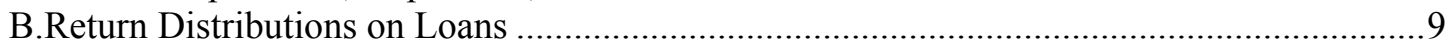

Base Returns and Random Schocks Thereto ............................................................ 9

Determinants of Base Loan Returns: Manager Competence ........................................... 10

C. Bank Interconnectedness (Asset Portfolio Diversification) ...............................................11

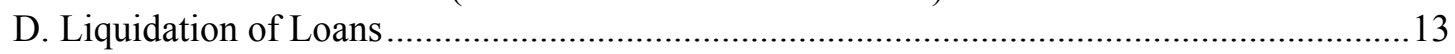

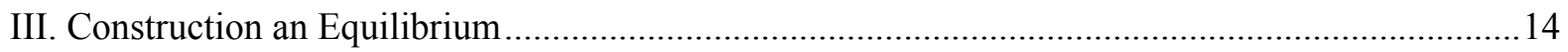

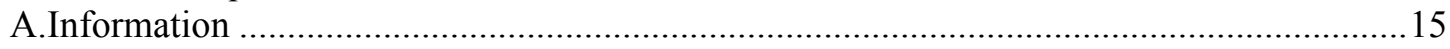

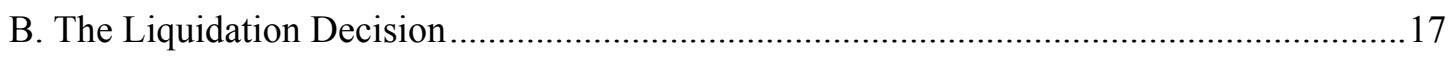

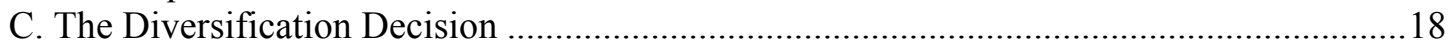

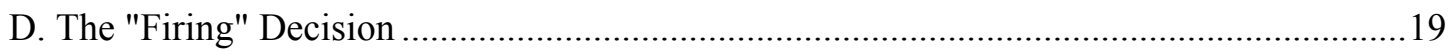

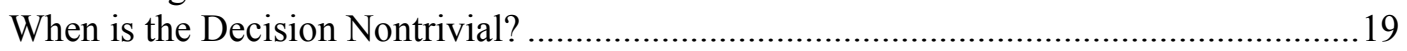

The Manager Replacement Decision When it is Not Trivial ............................................20

Looking for an Equilibrium in Which Both Banks Replace their Managers .....................21

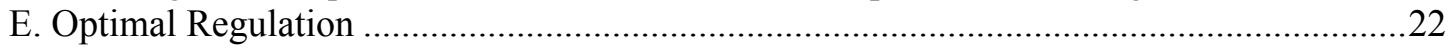

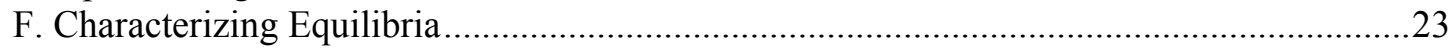

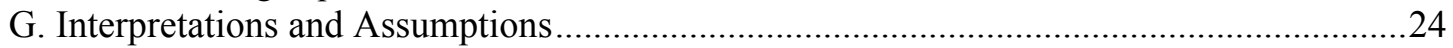

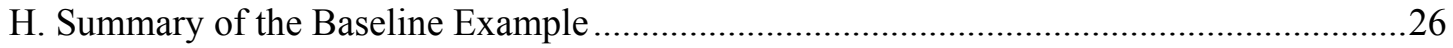

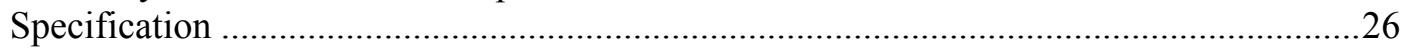

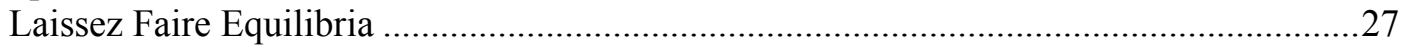

Equilibria Under Government Regulation ..........................................................28

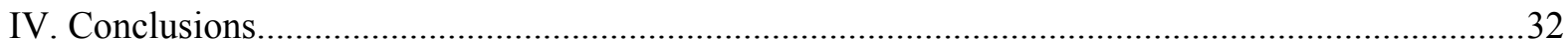

Tables

Table 1. Marginal and Joint Base Loan Return Distributions........................................................12

Figures

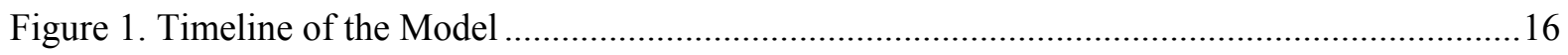

Appendixes

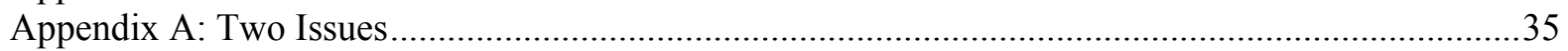

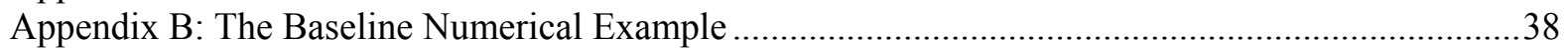

References

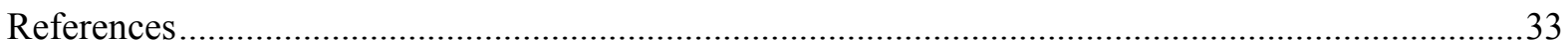




\section{INTRODUCTION}

The recent financial crisis affected an extremely large number of financial institutions, and was unusually severe. It was followed by a deep and prolonged recession (the "Great Recession"), and by an even longer period of economic malaise. By some accounts, the crisis began because of problems with the asset portfolios of large financial institutions that were interconnected to a degree that was very high, and probably unprecedented. These circumstances have created the impression that interconnectedness among financial institutions may make the economy more vulnerable to systemic financial crises, and they have reinforced the long-held belief that recessions that follow financial crises tend to be exceptionally severe. ${ }^{2}$ They have also produced proposals for government regulation to limit interconnectedness. ${ }^{3}$

Another widely held view about the recent financial crisis is that it was caused, at least in part, by a lack of complete and accurate information about the state of the portfolios of financial institutions. And a widely held view about the cause of the recession following the crisis is that credit became difficult to obtain, for risky borrowers, because financial institutions and their funders had lost confidence in the institutions' ability to assess credit risk effectively. ${ }^{4}$

The Financial Crisis Inquiry Report, prepared by the National Commission on the Causes of the Financial and Economic Crisis in the United States, summarizes many of these views clearly and succinctly (2011, page 10):

The crisis reached seismic proportions in September 2008 with the failure of Lehman Brothers and the impending collapse of the American International Group (AIG). Panic fanned by a lack of transparency of the balance sheets of major financial institutions, coupled with a tangle of interconnections among institutions perceived to be "too big to fail," caused the credit markets to seize up. Trading ground to a halt. The stock market plummeted. The economy plunged into a deep recession.

In this paper, we lay out a model whose predictions seem consistent with these views. In our model, "interconnectedness" means portfolio mixing (diversification) of loans originated by different financial institutions ("banks"). Examples of other papers in which it has a similar

\footnotetext{
${ }^{2}$ For recent evidence on this question, see Reinhart and Rogoff (2009) and Kannan et al. (2009). Jordá et al. (2014), use a new international data set and advanced econometric techniques to find that, over five-year recession/recovery periods, the cumulative output loss from recessions associated with financial crises, relative to other recessions, averages 20 percent of GDP.

${ }^{3}$ See, for example, the proposals discussed in Gambacorta and van Rixtel (2013).

${ }^{4}$ For safe borrowers, such as the Treasury and consumers with sterling credit, interest rates fell substantially.
} 
meaning include Bimpikis and Tabaz-Salehi (2012), Ibragimov, et al. (2011), and Wagner (2010, 2011). In all these papers, including ours, interconnectedness produces relatively adverse outcomes for portfolios held by banks at the time of a crisis. These adverse outcomes often arise because interconnectedness increases the likelihood that banks fail simultaneously. In Wagner's papers, simultaneous failures produce bad outcomes by necessitating "fire sales" of liquidated assets. In Bimpikis and Tabaz-Salehi, the joint failures simply produce very low returns on deposit portfolios, which are loathed by risk-averse depositors.

In our model, one of the problems caused by interconnectedness also involves bank asset liquidation. Interconnected banks may make inefficient liquidation decisions. Good assets may be liquidated at the same price as bad assets (a type of fire sale) and bad assets may go unliquidated, increasing the depth of the associated recession. These liquidation inefficiencies are symptoms of an underlying problem, which is that interconnectedness obscures information about the sources of banks' portfolio returns. However, joint failures (liquidation of the portfolios of both banks) can also be part of the mechanism that increases the likelihood that the recession will be long and severe.

Another difference between our model and some recent models in this literature, such as Wagner's models, is that diversification retains its traditional advantage from portfolio theory. We assume, along with Bimpikis and Tabaz-Salehi (2012), that depositors are risk averse, and that diversification tends to increase their welfare (expected utility) by reducing the variance of their returns, across portfolios and states of the world. ${ }^{5}$

In our model, interconnectedness has two potential disadvantages that may act to outweigh this advantage. The first disadvantage is related to an important strand of the literature on financial crises, which tries to explain the observation that their evolution seems to involve "contagion." Problems that start at one or a few institutions ultimately spread to many, and there is the impression that the problems at the institutions affected earlier cause or exacerbate the problems at those affected later. The classic recent contribution to this literature is Allen and Gale (2000). In these papers, the contagion occurs because low returns on loans originated by one institution hurt the returns on portfolios of connected institutions, directly or indirectly, increasing the likelihood that these institutions will fail.

Our two-bank model includes a simple form of contagion of this sort. When the banks are interconnected, the informational problem we referred to above may allow bad returns on loans initiated by one bank to cause both banks to liquidate their assets (fail), even though the loans initiated by the other bank would have yielded reasonably good returns. In this way, a financial crisis that could have been localized, resulting in the failure of only one bank, can be converted

\footnotetext{
${ }^{5}$ Ibragimov et al. (2011) assume that intermediaries must pay a premium for each unit of risk in their portfolios, but they do not endogenize this premium.
} 
into a systemic crisis, which has a relatively high cost in terms of lost output. In addition, the joint bank failures that characterize a systemic crisis are one of the ways in which information about banks' ability to assess risk can be obscured, reducing the efficiency of the banking system in the future (see below).

The second, and most important, disadvantage of interconnectedness, in our model, grows out of one of our basic assumptions about the economic role of banks. As Bernanke (2011) recently has emphasized, banks are useful partly because they have acquired "informational capital:" information about potential borrowers that allows them to assess credit risk relatively accurately. ${ }^{6}$ In our model, banks, or, more specifically, their managers, may not be equally skilled at risk assessment. A bank makes bad loans because its managers have turned out to be incompetent to assess credit risk, and need to be replaced. But when the portfolio of each bank includes loans initiated by the other bank, the identity of the bank whose loans produced a bad portfolio outcome may not be apparent. The result can be contagion, of a different kind: mistakes committed by bad managers may "infect" institutions whose managers are good, creating doubts about these managers' competence. As result, the managers of both banks may be replaced. But new managers have less informational capital (are less skilled at assessing credit risk) than experienced ones. So a situation in which part of the financial system suffers a temporary loss of informational capital can be transformed, via interconnectedness, into a situation in which the entire system suffers this loss (because one institution initiates bad loans, but both institutions fail, and both sets of managers are replaced). The result can be a substantial increase in the likelihood of low return outcomes on portfolios of loans initiated in the near future.

We think this "bad managers" story captures a view about the cause of the post-crisis recession which we summarized in the second paragraph of this introduction. According to this view, the huge losses suffered by many financial institutions during the crisis shook lenders' confidence in the ability of the financial system to assess credit risk effectively. As a result, it became more difficult for institutions to raise funds to finance risky loans, interest rates on these loans rose, and investment, employment and output declined. We describe a simple mechanism under which interconnectedness among financial institutions can allow bad outcomes on loans originated by some institutions to cause depositors to lose confidence, rationally, in the effectiveness of future risk assessment across the financial system.

The way we model the decision banks' depositors make about their managers causes the decision made by current depositors, and by current managers on the behalf, to influence the characteristics of the return distribution facing future depositors. This situation produces a business cycle, of

\footnotetext{
${ }^{6}$ See Greenwood and Jovanovic (1990), where banks contribute to the growth process by allowing investors to choose better projects and get higher rates of return, and Boissy et al. (2013), who use the assumption that banks are heterogeneous with respect to intermediation skills to generate an interbank loan market.
} 
sorts: in the model's second period, expected loan returns are lower, and recessions are more likely, than in its first period. Interconnectedness tends to increase the amplitude of this cycle.

The link between the decisions of current depositors and the returns received by future depositors also produces an intertemporal externality, because our assumptions imply that current depositors act to maximize their expected utility from current deposit returns. ${ }^{7}$ The government, however, cares about both current and future depositors. This situation creates a potential rationale for government intervention to restrict interconnectedness. The regulatory policy we study is simple: the government may limit or even prohibit interconnectedness. Although regulation of this sort is likely to reduce the attractiveness of the current deposit return distributions, by increasing their variability, it can increase future depositors' expected returns substantially, while also providing some benefits in terms of current expected returns. It does this by making the banking system more transparent. It becomes easier for depositors to use the information available to them to determine the characteristics of their banks' asset portfolios, and they can use this information to improve the efficiency of their liquidation and manager-replacement decisions.

For the moment, our description of the predictions of the model is based on a numerical example. While we hope to generalize the predictions at some point, the model is complicated enough that working with a numerical example seems like a reasonable first step.

In the next section, we lay out the main features of the model. The third section completes the description of the model, and presents its predictions, in the context of our baseline numerical example. The last section contains some concluding remarks.

\section{MODEL}

\section{A. Basic Setup: Banks, Depositors, Loans}

There are two periods. There are two ex ante identical banks that operate in both periods. Each period, each bank has an equal-measure continuum of one-period-lived depositors. (Again, see note 7 and appendix A.) These depositors are "tied" to the bank, perhaps for reasons of location. Each depositor has an endowment sufficient to fund one project. Depositors cannot consume their endowments, and they lack any capacity to manage projects.

\footnotetext{
${ }^{7}$ In the simplest version of the model, they do this because there are two cohorts of depositors, each of which lives for only one out of the model's two periods: see the next section. In appendix A, we argue that this assumption is not essential for our results: we can generate the same behavior when both the depositors and the government have the same (two-period) decision horizons.
} 
The banks use funds (endowments) from depositors to originate loans to finance projects: one project per depositor. The output of the projects is the single good the depositors consume.

Each project starts at the beginning of a period and is completed at the end of the same period. We assume that the loan returns are identical to the project returns: henceforth, we will usually refer to the loans and not the projects. In any period, all the loans originated by a particular bank (more specifically, by the current managers of that bank) have the same return distribution and yield the same return outcome. However, a bank's loan portfolio may include loans originated by the managers of the other bank.

The depositors of a bank are also its owners. The returns on a bank's portfolio are divided equally among its depositors. ${ }^{8}$ Each bank also has managers, who operate the bank in the interests of its current owner/depositors.

Each bank begins each period with incumbent managers: its depositors must decide whether to retain them or replace them. In period 2, a bank's incumbent managers are its managers from period $1 .{ }^{9}$

Each period, the managers of each bank are one of three types: experienced, inexperienced, or incompetent. These types are distinguished from each other by whether the managers managed a bank during the preceding period, and by the probability that the managers will make "good" loans (see below) during the current period. Experienced managers managed a bank last period and made good loans during that period. The probability that they will make good loans this period is positive and relatively high. Inexperienced managers did not manage a bank last period. The probability they will make good loans this period is positive but relatively low. Incompetent managers managed a bank last period and made bad loans during that period. The probability that they will make good loans this period is zero.

We assume that, in period 1, each bank's incumbent managers are experienced: we will say more about this assumption below. We also assume that if a bank hires new managers, these managers are inexperienced. ${ }^{10}$

\footnotetext{
${ }^{8}$ These are banks of a fairly simple sort: they pool funds and spread risk, but they don't transform terms or reallocate risk by issuing liabilities with different risk characteristics.

${ }^{9}$ Although there is no period 0 , we can think of the situation at the beginning of period 1as being "as if" the incumbent managers had managed their respective banks in period 0: see below.

${ }^{10}$ Since there are only two banks, a bank could hire experienced new managers, in period 2, only by hiring them away from the other bank. We rule this out by assuming that experienced managers prefer to stay with the bank they worked for in the preceding period, if they have that option. (We are not trying to model the compensation received by bank managers.)
} 
When the depositors of a bank make decisions, or when the current managers of a bank make decisions on behalf of its current depositors, they do so in order to maximize the depositors' expected utility from consumption, calculated using the constant-relative-risk-aversion utility function $u(c)=\left(c^{1-\gamma}-1\right) /(1-\gamma)$, for $\gamma>0$. We consider three alternative values for $\gamma$ : $\gamma=1$ [in which case $u(c)=\ln c$ ], $\gamma=2$ and $\gamma=4$. We will think of $\gamma=1$ as the case where the depositors are not very (are weakly) risk averse, $\gamma=2$ as the case where they are moderately risk averse, and $\gamma=4$ as the case where they are strongly risk averse. We do this because $\gamma=1$ is at the low end of the range of empirical estimates of the coefficient of relative risk aversion, while $\gamma=4$ is widely used to represent the behavior of agents who are fairly strongly risk averse.

\section{B. Return Distributions on Loans}

\section{Base Returns and Random Shocks Thereto}

The return outcome on the loans originated by the managers of a particular bank, in a period, is a random variable that consists of the sum of a "base return," which is itself random, and a relatively small random shock. There are two possible base return outcomes, "good" and "bad": $g$ or $b$ units of the good, respectively, per depositor, where $0 \leq b<g$. (In our baseline example, $g=1$ and $b=\frac{1}{2}$

.) There are two possible random shocks associated with each possible base return outcome: $\pm \varepsilon^{g}$ for the good outcome, equally likely, and $\pm \varepsilon^{b}$ for the bad outcome. These shocks are independent across banks and periods. We assume $\varepsilon^{g}>\varepsilon^{b} \geq 0, \varepsilon^{g}<g$, and $\varepsilon^{b}<b$. (We work through two versions of the baseline example: these are identical to each other except that first one, which is relatively simple, features $\varepsilon^{b}=0$, while the second one features $\varepsilon^{b}=\frac{1}{12}$.)

The base return distributions for loans originated by the two banks are independent across periods, but they are correlated with each other, within each period, in a way that makes it impossible for both sets of loans to yield bad base returns. We say more about this assumption, and why we make it, below.

We make two additional assumptions that are especially important for the feature of our model that leads to portfolio liquidation by bank managers, under some circumstances (see below).

Assumption 1: $b+\varepsilon^{b}<q<g-\varepsilon^{g}$.

Note that this assumption also ensures that our (risk averse) depositors will always view our "good" base return as good, because its total return pattern, including the random shocks, stochastically dominates the pattern associated with our "bad" base return.

Assumption 2: $(1-\theta)\left(g-\varepsilon^{g}\right)+\theta\left(b-\varepsilon^{b}\right)<q<\theta\left(g+\varepsilon^{g}\right)+(1-\theta)\left(b-\varepsilon^{b}\right)$. 


\section{Determinants of Base Loan Returns: Manager Competence}

Marginal returns. The loans originated by a bank's managers will yield the good base return if the managers have the ability to distinguish good projects from bad ones, in which case we say they are "competent." Since there are measure-zero good projects among the continuum of potential projects, incompetent managers always choose bad projects.

If the current managers of a bank also managed the bank last period, and originated good loans (loans that yielded the good base return), then we say they are experienced, this period. In this case, the probability they are competent is denoted $p^{e}$. We assume $1 / 2<p^{e}<1$. (In our baseline example, $p^{e}=3 / 4$.) If the current managers of a bank originated bad loans, last period, then we say they are incompetent, and the probability they will make good loans, this period, is zero. Finally, if the current managers of a bank did not originate loans last period, we say they are inexperienced, and the probability they will be competent, this period, is denoted $p^{i}$; we assume $0<p^{i}<p^{e}$. (In our baseline example, $p^{i}=1 / 2$.) If incumbent managers are either experienced or inexperienced, we sometimes refer to them as ex ante competent, because it is possible that they will turn out to be competent.

Joint base returns. In any period, the joint distribution of the base returns on the loans originated by the managers of the two banks - which must, of course, be consistent with the marginal distributions - depends on the characteristics of both sets of managers. As we have indicated, one of our key assumption about this distribution is that, if neither set of managers made bad loans last period - which is true in period 1, by assumption: see below - then the probability that both sets will originate bad loans, this period, is zero.

Unmixed returns: If the loans originated by both sets of managers turn out to be good, we call the joint base return outcome "unmixed." When both sets of bank managers are experienced, the probability of an unmixed outcome is denoted $p^{e e}$. When both sets of managers are inexperienced, it is denoted $p^{i i}$.

Mixed returns: If the loans originated by one set of managers turn out to be good, while those originated by the other set turn out to be bad, we call the joint base return outcome "mixed" and we say it "favors" the first bank. We assume that when both sets of managers have the same experience characteristics, the probabilities of mixed joint base return outcomes favoring each bank are equal. So we must have $p^{e e}+\left(1-p^{e e}\right) / 2=p^{e} \Leftrightarrow p^{e e}=2 p^{e}-1$ and $p^{i i}+\left(1-p^{i i}\right) / 2=p^{i}$ $\Leftrightarrow p^{i i}=2 p^{i}-1$. It follows that we must require $p^{i} \geq 1 / 2$ (a condition just satisfied in our baseline example) and that $0 \leq p^{i i}<p^{e e}$. (In our baseline example, $p^{e e}=1 / 2$ and $p^{i i}=0$.) 
If one set of managers is experienced, and the other set is inexperienced, then the probability of an unmixed return outcome is denoted $p^{e i}$. We must have $p^{e}=p^{e i}+p^{m e}\left(1-p^{e i}\right)$ and $p^{i}=p^{e i}+\left(1-p^{m e}\right)\left(1-p^{e i}\right)$, where $p^{m e}$ is the probability that the joint base return outcome favors the experienced managers, conditional on the outcome being mixed. It follows that $p^{e i}=p^{e}+p^{i}-1$ and $p^{m e}=\left(1-p^{i}\right) /\left(1-p^{e i}\right)$, and that $p^{i i}<p^{e i}<p^{e e}$. Thus, the probability of an unmixed joint base return outcome increases with the experience level of the managers. (In our baseline example, $p^{e i}=1 / 4$, and $p^{m e}=2 / 3$ ).

The base loan return assumptions for our baseline example are summarized in Table 1 on the next page.

\section{Bank Interconnectedness (Asset Portfolio Diversification)}

The managers of the two banks can diversify their banks' asset portfolios by exchanging loans they have originated for loans originated by the managers of the other bank. We study three alternative portfolio diversification regimes: no diversification (ND), in which case each bank's portfolio consists entirely of loans its managers originated, partial diversification (PD), in which case each bank's portfolio consists partly of loans it originated and partly of loans the originated by the managers of the other bank, with the former predominating, and complete diversification (CD), in which case each bank's portfolio is equally divided between loans its managers originated and loans originated by the managers of the other bank.

We will let $d$, for either bank, represent the ratio of loans, in its portfolio, originated by the managers of the other bank, to loans originated its own managers. So we will study the cases $d=0$ (ND), $d=1$ (CD), and some particular value $d$ satisfying $0<d<1$ (PD). It is often more convenient to work with the parameter $\theta=d /(1+d)$, which is the fraction of a bank's portfolio that consists of loans originated by the managers of the other bank, so that $\theta \in\left(0, \frac{1}{2}\right)$ under PD. Henceforth, an unsubscripted $\theta$ refers to the value of this parameter under PD. (In our baseline example, we choose $d=\frac{1}{2}$ for $\mathrm{PD}$, which is $\theta=\frac{1}{3}$.)

We confine ourselves to these three alternatives because we want to generate information problems in a simple model, where we can work with discrete probability distributions and avoid complex problems of statistical inference. 


\section{Table 1 \\ Marginal and joint base loan return distributions}

Baseline example

Marginal outcomes in regular type

Joint outcomes in italics

Both banks' managers are experienced

Bank B

\begin{tabular}{|c|c|c|c|}
\hline \multirow{3}{*}{ Bank A } & & $\begin{array}{l}\text { Good outcome } g \\
p^{e}=3 / 4\end{array}$ & $\begin{array}{l}\text { Bad outcome } b \\
1 / 4\end{array}$ \\
\hline & $\begin{array}{l}\text { Good outcome } g \\
p^{e}=3 / 4\end{array}$ & $\begin{array}{l}\text { Unmixed outcome } \\
p^{e e}=1 / 2\end{array}$ & $\begin{array}{l}\text { Mixed favoring } A \\
1 / 4\end{array}$ \\
\hline & $\begin{array}{l}\text { Bad outcome } b \\
1 / 4\end{array}$ & $\begin{array}{l}\text { Mixed favoring } B \\
1 / 4\end{array}$ & 0 \\
\hline
\end{tabular}

Bank A's managers are experienced, Bank B's are inexperienced

Bank B

\begin{tabular}{|c|c|c|c|}
\hline \multirow{3}{*}{ Bank A } & & $\begin{array}{l}\text { Good outcome } g \\
p^{i}=1 / 2\end{array}$ & $\begin{array}{l}\text { Bad outcome } b \\
1 / 2\end{array}$ \\
\hline & $\begin{array}{l}\text { Good outcome } g \\
p^{e}=3 / 4\end{array}$ & $\begin{array}{l}\text { Unmixed outcome } \\
p^{e i}=1 / 4\end{array}$ & $\begin{array}{l}\text { Mixed favoring } A \\
1 / 2\end{array}$ \\
\hline & $\begin{array}{l}\text { Bad outcome } b \\
1 / 4\end{array}$ & $\begin{array}{l}\text { Mixed favoring } B \\
1 / 4\end{array}$ & 0 \\
\hline
\end{tabular}

Here $p^{m e}=2 / 3$, so that a mixed outcome favoring Bank A is twice as likely as a mixed outcome favoring Bank B.

\section{Both banks' managers are inexperienced}

\section{Bank B}

\begin{tabular}{|c|c|c|c|}
\hline \multirow{3}{*}{ Bank A } & & $\begin{array}{l}\text { Good outcome } g \\
p^{i}=1 / 2\end{array}$ & $\begin{array}{l}\text { Bad outcome } b \\
1 / 2\end{array}$ \\
\hline & $\begin{array}{l}\text { Good outcome } g \\
p^{i}=1 / 2\end{array}$ & $\begin{array}{l}\text { Unmixed outcome } \\
p^{i i}=0\end{array}$ & $\begin{array}{l}\text { Mixed favoring } A \\
1 / 2\end{array}$ \\
\hline & $\begin{array}{l}\text { Bad outcome } b \\
1 / 2\end{array}$ & $\begin{array}{l}\text { Mixed favoring } B \\
1 / 2\end{array}$ & 0 \\
\hline
\end{tabular}


Here is a relatively concise general characterization of the sets of potential total loan return outcomes, for the two banks $\{A, B\}$, under each of the three diversification regimes:

If we let $\theta_{h}, h=1,2,3$ represent the $\theta$-values for $\mathrm{ND}, \mathrm{PD}$, and $\mathrm{CD}$, respectively, so that $\theta_{1}=0$, $\theta_{3}=\frac{1}{2}$, and $\theta_{1}<\theta_{2}<\theta_{3}$, and if we let $\varepsilon_{i}^{v}=(-1)^{i-1} \varepsilon^{v}, v=g, b i=1,2$, then we can characterize the set of potential joint portfolio return outcome pairs for the two banks $\{A, B\}$, for each diversification regime $s$, as follows:

$$
\left\{\begin{array}{r}
\left\{\left(1-\theta_{h}\right)\left(g+\varepsilon_{i}^{g}\right)+\theta_{h}\left(g+\varepsilon_{j}^{g}\right),\left(1-\theta_{h}\right)\left(g+\varepsilon_{j}^{g}\right)+\theta_{h}\left(g+\varepsilon_{i}^{g}\right)\right\} \\
\cup\left\{\left(1-\theta_{h}\right)\left(g+\varepsilon_{i}^{g}\right)+\theta_{h}\left(b+\varepsilon_{j}^{b}\right),\left(1-\theta_{h}\right)\left(b+\varepsilon_{j}^{b}\right)+\theta_{h}\left(g+\varepsilon_{i}^{g}\right)\right\} \\
\cup\left\{\left(1-\theta_{h}\right)\left(b+\varepsilon_{j}^{b}\right)+\theta_{h}\left(g+\varepsilon_{i}^{g}\right),\left(1-\theta_{h}\right)\left(g+\varepsilon_{j}^{g}\right)+\theta_{h}\left(b+\varepsilon_{i}^{b}\right)\right\}
\end{array}\right\}, h=1,2,3, i=1,2, j=1,2 .
$$

Thus, in the first, simpler version of our baseline example, there are eight joint total return outcomes, four associated with unmixed base loan return outcomes, and four associated with mixed outcomes. In the second, more complicated version, there are twelve total loan return outcomes, four associated with unmixed base loan return outcomes, and eight associated with mixed. Collectively, the four unmixed total loan return outcomes comprise the first element of a three-element set that includes all the joint total return outcomes. The other elements of that set are the mixed joint total return outcomes favoring Bank A and Bank B, respectively. In Version 1 of the model, there are two mixed joint total loan return outcomes favoring each bank, while in Version 2, there are four.

As we shall see, the set of realized total loan return outcomes differs from the set of potential return outcomes in that, if any of the potential portfolio total return outcomes has a value less than the liquidation value $q$, its realized value becomes $q$, in equilibrium.

\section{Liquidation of Loans}

At a fixed moment "in the middle" of each period, after loans have been extended and projects have been initiated, but before projects have been completed and loans repaid, a bank can enforce liquidation of any fraction of the projects that have been financed by loans in its portfolio.

Liquidating a project yields $q$ units of the good. These $q$ units become the repayment on the loan that financed the project.

Since liquidation must occur quickly, we assume that a bank can't control which of the projects in its portfolio are liquidated. (We will say more about this assumption below.) The fraction of the projects liquidated by a bank that were financed by loans originated by the managers of that bank is equal to $1-\theta$, the fraction of those loans in the bank's portfolio. 
Banks liquidate projects in response to withdrawal requests from depositors. At the same moment that liquidation is possible, each depositor has a right to withdraw her deposit, obtaining a payment of $q$ but forfeiting any share of the end-of-period deposit return. Immediately prior to this moment, the managers and depositors of each bank receive a private signal about the fate of the bank's portfolio. The signal, which is perfectly accurate, indicates whether the average loan repayment will exceed $q$ (a favorable signal) or fall short of $q$ (an unfavorable signal). The signal does not provide any information about the components of the portfolio, if there are any: that is, it provides no information about differences in the returns on loans originated by the managers of different banks.

As we have noted, we have made two supplementary return assumptions that have two important implications for the nature if the situations in which liquidation occurs. Assumption 1 ensures that if the joint return outcome will be unmixed then neither bank will get the unfavorable signal, regardless of the diversification regime. It also ensures that if the banks' portfolios are not diversified then at most one bank gets the unfavorable signal.

Assumption 2 implies that, if there is any diversification (PD or CD), then it is possible for both banks to get the unfavorable signal (the left-hand side inequality), and that, if the joint return outcome is mixed and the good loans get the high shock, then it is not possible for either bank to get the unfavorable signal (the right-hand side inequality). ${ }^{11}$ (For our baseline example, we choose $q=\frac{5}{8}$, and it is readily seen that both versions satisfy these two assumptions.)

\section{CONSTRUCTING AN EQUILIBRIUM}

An equilibrium in this model involves decisions by bank depositors and decisions by bank managers. These decisions depend critically on the information available to these agents at the time these decisions are made. Each period, each bank's depositors must choose, at the beginning of the period, whether to replace or retain the incumbent managers of the bank. In period 2, this decision is complicated by the fact that the depositors may not have complete information about the managers' competence. Each period, the first decision the retained or newly hired managers of the two banks must make is how completely to diversify the banks' portfolios. In period 2, this decision depends partly on the banks' return outcomes from period 1 , which influence the experience levels of the banks' managers. Later, the managers must

\footnotetext{
${ }^{11}$ These two assumptions, taken together, impose a joint restriction on $\theta$ and $q$. For $\theta=0$, it is clear that $(1-\theta)\left(g-\varepsilon^{g}\right)+\theta\left(b-\varepsilon^{b}\right)>\theta\left(g+\varepsilon^{g}\right)+(1-\theta)\left(b-\varepsilon^{b}\right)$, but the inequality is necessarily reversed for an interval of $\theta$-values below $1 / 2$. In addition, it can be shown that if $\theta$ is below but sufficiently close to $1 / 2$, there are $q$-values satisfying both $(1-\theta)\left(g-\varepsilon^{g}\right)+\theta\left(b-\varepsilon^{b}\right)<q<\theta\left(g+\varepsilon^{g}\right)+(1-\theta)\left(b-\varepsilon^{b}\right)$ and $b+\varepsilon^{b}<q<g-\varepsilon^{g}$.
} 
choose whether or not to liquidate the banks' assets. This decision is complicated by the fact that, if the banks' portfolios are diversified, the managers do not have complete information about the returns on these assets.

A time line of events and decisions in the model is presented in Figure 1 on the next page.

The decisions of the depositors and the managers depend critically on the information available at the moments when they make them. This is the question to which we now turn.

\section{A. Information}

All the agents in the model know its basic structure, including the distributions of manager competence and loan returns, the return from liquidation, the nature of the interim signal, the return implications of the possible diversification regimes, and the roles and motives of the other agents.

The diversification decision made by the managers of the two banks is publicly observable, as are the amounts the banks pay their depositors. Consequently, the depositors and managers in period 2 know this information for period 1.

In each period, the interim signal about each bank is observed only by the depositors and managers of that bank.

At the beginning of period 2, the banks' new depositors know only as much about the competence of the banks' incumbent managers as they can infer from their knowledge of the diversification regime in period 1 and the returns paid to the period- 1 depositors.

In period 2, the incumbent managers know whether or not they made good loans during the preceding period, whether or not the depositors of the banks can infer this information. As we shall see, however, in situations where the depositors cannot infer it, the managers cannot reveal it credibly.

Although there is no period 0 , we assume that, at the beginning of period 1, the depositors and managers have knowledge analogous to knowledge they might have been able to infer, from information of the type just described, if there had been a period 0 and certain events had occurred during that period (see below). In particular, we assume that both banks' managers and depositors know that the banks' managers are experienced. 


\section{Figure 1. The time line of the model}

\section{Beginning}

- The banks' depositors make their (trivial) retention/replacement decision, retaining their incumbent managers.

- The banks' managers make their lending and diversifications decisions. Both sets of managers are experienced.

\section{Middle}

- Each bank's managers and depositors receive a signal about the bank's portfolio return.

- The banks' depositors make their liquidation decisions.

- The banks' managers liquidate loans as necessary.

\section{End}

Portfolio returns are observed and paid.

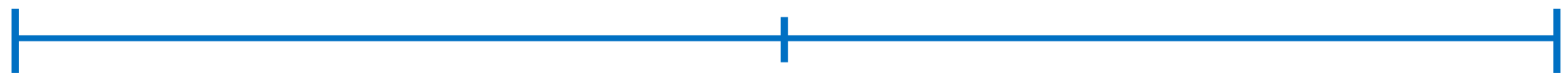

Period 1

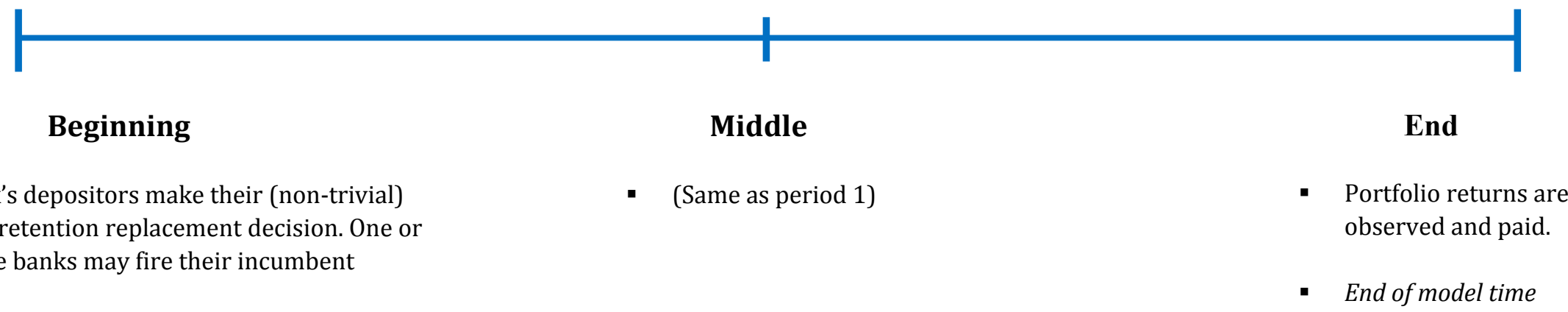

- The banks' managers make their lending and diversification decisions, which are complicated by the fact that one or both sets of managers may be inexperienced. 
A key information assumption of our model is that a bank's depositors do not observe the returns on the loans originated by either bank: they observe only the banks' portfolio returns. This assumption may seem strong. It reflects the widely held view, described in our introduction, that the fact that bank loan portfolios often included many loans originated by other banks made it difficult for financial market participants to determine the value of the portfolios, which in turn made it difficult for banks to attract or retain funds during the recent financial crisis. We think this situation may also have had the effect of making it difficult for the market to determine whether a bank's managers had competently assessed the risks on the loans they had originated. The purpose of this paper is to explain why portfolio opacity may have had these two effects, and what the consequence of these effects may have been. But we are not, at this stage, trying to diagnose the source of the opacity.

\section{B. The Liquidation Decision}

Our liquidation assumptions are constructed with an eye to ensuring that a bank's depositors withdraw all their deposits, and its managers liquidate the bank's entire loan portfolio, if the interim signal is unfavorable, and that no deposits are withdrawn or loans liquidated otherwise.

The assumption that the managers of a bank can't control which loans they liquidate - that is, that they liquidate loans they originated, and loans originated by the managers of the other bank, in the proportions they represent in the bank's portfolio - is important, for this purpose.

Otherwise, there are situations in which the depositors of a bank might not choose to withdraw their deposits, in response to the bad signal, because they expect the bank's managers to liquidate only the loans in its portfolio that they originated, or only the loans the other bank's managers originated. They might do this because the information available to them suggests that it is relatively likely that the loans originated by the managers in question are bad. ${ }^{12}$

In order avoid complications that result from the fact that the depositors are risk averse, and that individual loans must have good or bad base returns, we define the liquidation component of our equilibrium in the following way. We assume all depositors liquidate (do not liquidate) their deposits in response to the unfavorable (favorable) sign if an individual depositor, who observed that all the depositors except for a small positive-measure group had liquidated (not liquidated), would decline to join this small group. Under this assumption, it is clear that a depositor who

\footnotetext{
${ }^{12}$ An alternative might be to strengthen our assumptions so that it is never possible for either bank's managers to infer that the loans originated by one bank are more likely to have been bad than those originated by the other. We have chosen not to try to do that. We see the assumption that bank managers can't choose which loans to liquidate as related to the assumption that bank depositors can't observe the returns on loans, by originator. Both assumptions are part of the underlying thematic assumption of our model, which is that interconnectedness (loan portfolio diversification) obscures information about the contents of bank loan portfolios. In this case, we are imagining that the managers need to liquidate loans in a hurry, and that collecting reliable information about the originators of particular loans might take a good deal of time.
} 
sees the unfavorable signal will liquidate: if she liquidates, she will get a return of exactly $q$, and if she does not, she will get a return less than $q$, both with certainty. Similarly, a depositor who sees the favorable signal will not liquidate, because declining to liquidate will guarantee her a return that exceeds $q$.

\section{The Diversification Decision}

Each period, the managers of the two banks make a portfolio diversification decision, collectively choosing ND, PD or CD. Although they make this decision after the depositors make their manager retention/replacement decision, the depositors make that decision in light of their knowledge of the diversification decisions managers will make under various scenarios involving their experience and competence.

We assume that, with one exception (see below) a bank's managers make their diversification decisions in order to maximize the expected utility of its depositors. If there is disagreement about the desired degree of diversification - which can be the case if the two sets of managers have different levels of experience, or if one set is not ex ante competent - then we assume they choose the most extensive degree of diversification that provides a marginal benefit to both, relative to next most extensive degree. (For example, if one set of managers prefers PD to ND or $\mathrm{CD}$, the other set prefers CD to PD and PD to ND, then both sets choose PD.)

As we have seen, the managers of each bank always know the experience/competence characteristics of the managers of both banks. If one bank's managers are incompetent then the other bank's managers will always decline to diversify with them, and the diversification regime will be ND. This situation can occur only in period 2, and only in situations where the depositors of the two banks know that one set of managers was incompetent, last period, but cannot determine which one (see below). Otherwise, the extent of the diversification depends on the return distributions, the competence characteristics of the managers, and the depositors' degree of risk aversion.

In our baseline example, if both banks' managers are experienced then $\mathrm{CD}$ is the best choice, for any degree of depositor risk aversion. Thus, if the banks are unregulated then CD always prevails in period 1; and it always prevails in period 2, regardless of regulation (which does not constrain banks in period 2), if the period 1 return outcome was unmixed. When one bank's managers are experienced and the others are inexperienced, the choice is ND in both versions, if the depositors are weakly risk averse; if they are moderately risk averse, the choice is CD in Version 1 but ND in Version 2; if they are strongly risk averse, it is CD again in Version 1, but PD in Version 2. If both banks' managers are inexperienced, they choose ND, in both versions, if risk aversion is weak, and $\mathrm{CD}$, in both versions, if it is moderate or strong. 


\section{The "Firing" Decision}

At the beginning of each period, the depositor/owners of each of the two banks must decide whether to retain or replace ("fire") the bank's incumbent managers. They will replace the managers if doing so increases their expected utility.

Clearly, a bank's managers should be retained if they are competent and replaced if they are incompetent. Unfortunately, a bank's depositors typically cannot be certain whether the bank's current managers are competent. Part of the reason for this is that depositors cannot observe manager competence, directly: they can only infer it from their past performance, and from their knowledge of the distribution of competence among managers. Another part is that the sources of risk on bank projects may change from period to period, for reasons we do not model. These changes can cause previously competent managers to lose their competence. For this reason, the fact that a bank's managers originated good loans in period 1 does not guarantee that they will repeat that performance in period 2.

Nevertheless, our assumptions guarantee that a bank's depositors will retain the bank's incumbent managers if they are certain these managers originated good loans, last period (or, in period 1 , if they have equivalent information) and that they will replace its former managers if they are certain these managers made bad loans, last period. As we shall see, the only other possibility is that they are uncertain, in the sense that it is equally likely that the incumbent managers originated good loans or bad loans last period.

\section{When is the Decision Nontrivial?}

In period 1, we assume the depositors of both banks know that the incumbent managers of both banks are experienced ("as if" they can infer that these managers made good loans last period: see below). Each group of depositors will choose to retain their bank's incumbent managers, because experienced managers make good loans more often than inexperienced ones.

As we have seen, the information the period-2 depositors have to assess the qualifications of their banks' incumbent managers includes the structure of the model, the nature of the diversification regime in period 1, and the return received by each bank's depositors in period 1. They do not directly observe the returns on the loans originated by either bank. If either bank liquidated its assets, they know it, because the bank's depositors will receive a return equal to the liquidation value.

We now turn to the question of which period-1 return outcomes produce which managerexperience situations in period 2: two sets of experienced managers, one set, or no sets. (In both the latter cases, the other set of managers is inexperienced.) 
If the joint return outcome from period 1 was unmixed, the depositors of both banks can infer that, regardless of the diversification regime. They consequently can infer that the managers of both banks were competent. The reason this is true begins with the fact that no unmixed joint return outcome can produce an average return, across the two banks, as large as $g$. And only one mixed joint return outcome can produce an average return lower than $g$ : the outcome in which both shocks are low, so that both banks' depositors get a return of $g-\varepsilon^{g}$, regardless of the diversification regime. Under ND or PD, it is impossible for a mixed joint return outcome to deliver equal returns to the depositors of both banks. Under CD, all joint return outcomes deliver equal depositors returns, but Liquidation Assumption 1 guarantees that the average return, across the two banks, is never equal to $g-\varepsilon^{g}$.

If the joint return outcome from period 1 was mixed, and the diversification regime was ND, the depositors know immediately which bank's managers were incompetent: it is the managers of the bank that paid the lower return. The same thing is readily seen to be true under PD, provided both banks did not liquidate their portfolios.

Thus, there are two types of combinations of diversification regime and joint return outcome that produce uncertainty about manager competence: under PD, any joint mixed return outcome that produces portfolio liquidation by both banks; under $\mathrm{CD}$, any joint mixed return outcome of any sort - whether or not there is liquidation - because the depositors of both banks always receive the same return. In any of these cases, the return outcome is known to have been mixed, so the depositors of both banks know that the managers of one of the two banks were incompetent. But since the two portfolio return outcomes were identical, they have no way of knowing which bank it was. ${ }^{13}$ (In the first version of our first baseline example, when the banks are interconnected they both fail whenever there is a mixed outcome with a low shock to the good base return, regardless of the diversification regime. In the second version, however, only one bank fails, under PD, if a low shock to the good base return is accompanied by a high shock to the bad one.)

\section{The Manager Replacement Decision when it is not Trivial}

If the joint return outcome from period 1 does not reveal which bank's incumbent managers (if any) were incompetent, in that period, then we model the manager-replacement decision, in period 2, as a non-cooperative game between the depositors of the two banks. The rationale for this approach is that the distribution of return outcomes resulting from a particular manager-

\footnotetext{
${ }^{13}$ Obviously, CD is very special, in this sense: in cases where both banks do not liquidate, even a tiny departure from a 50-50 portfolio split would create differences between the joint returns received by the two banks, allowing depositors to infer the identity of the bank that originated bad loans. We choose CD as one of our three regimes because we think of the model presented here as a proxy for a more complicated model with additional sources of continuously distributed noise affecting the return distributions. In such model, if the diversification regime was close to $\mathrm{CD}$ then inference about the identity of the bank that made the bad loans would be very unreliable.
} 
replacement decision, by one bank, may depend on the manager-replacement decision of the other bank. We assume each bank's depositors make the replacement decision that produces the return distribution that maximizes their expected utility. We will stick to pure strategies, and we will look for a Nash equilibrium: in particular, an equilibrium in which the managers of both banks are replaced.

We assume that the banks' incumbent managers know how they performed last period (whether they made good loans, or not) but can't credibly reveal their performance, because they lose satisfaction from being revealed to have been incompetent. ${ }^{14}$ They also know the performance, last period, of the other managers of the other bank, because it has to have been the opposite of their performance. Finally, we assume manager replacement is publicly observed, so that the current managers of each bank (incumbents or replacements) know whether the current managers of the other bank are inexperienced.

\section{Looking for an Equilibrium in which Both Banks Replace their Managers}

Suppose the depositors of Bank B (for example) choose to replace its managers, so that its new managers are inexperienced. If the depositors of Bank $A$ also replace its managers, then both banks will have inexperienced managers. The resulting return distribution will depend on whether the inexperienced managers of one bank will choose to diversify their bank's portfolio with the portfolio of another bank with inexperienced managers, and, if so, which degree of diversification they will choose: see above.

If the depositors of Bank A do not replace its managers, then two things can happen. If Bank A's managers are incompetent, then Bank B's managers will not agree to diversify with Bank A. Bank A's depositors will receive a low base return with certainty, and Bank B's depositors will face the marginal return distribution for loans by inexperienced managers. Otherwise, Bank A's managers are experienced. What happens next depends on whether experienced managers choose to diversify their loan portfolios with loans made by inexperienced managers, and, if so, how completely: again, see above.

For a given level of intensity of depositor risk aversion, if the expected utility received by a bank with inexperienced managers, when the managers of the other bank are also inexperienced (eu-ii), exceeds the average of the expected utility received by a bank with incompetent managers (eu- $n)$ and the expected utility received by a bank with experienced managers when the managers of the other bank are inexperienced (eu-ei), then there is a Nash equilibrium in which both banks replace their managers. (This is true in both versions of our baseline example.)

\footnotetext{
${ }^{14}$ Situations of this type are the only ones in which managers may take (or fail to take) actions that are not in the interests of their depositors.
} 
In appendix A, we describe the process that can be used to check the uniqueness of this equilibrium. (It is unique in both versions of our baseline example.)

The complications associated with risk aversion make it impossible for us to provide a general characterization of the specifications under which there is a unique equilibrium in which both banks replace their managers, in period 2, when the competence of the period-1 managers is unknown. In what follows, we will assume the specification has this property.

\section{E. Optimal Regulation}

We assume the government's goal is to maximize the average ex ante expected utility of period 1 and 2 depositors, under the assumption that depositors do not know which bank they will be associated with. As we have seen, in period 1 the depositors of each bank are assumed to act to maximize their expected utility, ignoring the fact that their actions, and the actions bank managers take on their behalf, affect the outlook for depositors in period 2. This situation creates a possible rationale for government intervention, in period 1. There is no such rationale in period 2 , when the interests of the government and the depositors are aligned.

We assume the government has a simple set of regulatory options, in period 1: it can do nothing, in which case the managers of the banks will choose the diversification regime that maximizes the utility of their period-1 depositors, or it can restrict banks' degree of diversification by ruling out one or two of the three diversification regimes. For example, if the banks prefer $\mathrm{CD}$, in period 1, the government can rule out $\mathrm{CD}$, allowing the banks to choose PD or ND, or it can rule out both $\mathrm{CD}$ and $\mathrm{PD}$, forcing them to choose ND. In period 2, the managers of the banks are always free to choose the diversification regime that maximizes the expected utility of their depositors.

We begin by choosing a particular level of intensity of risk aversion, which is assumed to be shared by all the depositors. Next, we determine the ex ante expected utility of a depositor of this type, in the absence of government regulation. We assume that the depositor may live either in period 1 or in period 2, and, in either case, that her deposits may be in either bank. We also assume, for the purposes of this discussion, that if there is a mixed joint return outcome in period 1 , and if the identity of the bank whose managers made the bad loans cannot be determined, then the managers of both banks are replaced (see above).

Absent regulation, the banks in period 1 choose the diversification regime that maximizes the expected utility of the period- 1 depositors. Because of the potential losses from inefficient liquidation (liquidation of loans that will turn out to be good, or non-liquidation of loans that will turn out to be bad), this regime is not necessarily $\mathrm{CD}$, although it is $\mathrm{CD}$ in our baseline example: see below. 
The choice of the diversification regime in period 1 determines the probabilities of the three possible states in period 2: a state where both sets of managers are experienced, a state where one set of managers is experienced and the other set is inexperienced, and a state where both sets of managers are inexperienced. If there is a Nash equilibrium with replacement (see above) then there is no state in which either set of managers is ex ante incompetent.

Next, we work out the return distribution received by the depositors of each bank, in each of these states, given that a bank's managers, in period 2, choose the degree of diversification that is optimal for their period-2 depositors. Since there is no period 3, there is no reason for the government to choose a diversification regime that is different from the regime the bank managers (and, thus, the depositors) would choose. We can determine depositors' expected utility, in each state, from the return distributions. Note that in the experienced-inexperienced state, we must average the expected utility received by the depositors of the bank with experienced managers and that of the depositors of the other bank. In the other two states, the depositors of both banks get the same expected utility.

The government may prefer less diversification, in period 1, than happens absent regulation, because of the external costs that complete or partial diversification may impose on period-2 depositors. In these cases, there is a welfare rationale for government regulation that limits or even prohibits diversification (interconnectedness).

\section{F. Characterizing Equilibria}

An equilibrium in this model is a description of the distribution of the return outcomes for the depositors in period 1 and period 2, given our assumptions, including assumptions about the behavior of the agents in the model.

In period 1, the depositors of both banks make a trivial manager firing decision: both banks' depositors retain their incumbent managers. The managers choose the diversification regime that maximizes the expected utility of their depositors, given the constraints that may be imposed by the government, which may prohibit diversification (imposing ND) or limit diversification (prohibiting CD). In the middle of the period, the depositors of a bank withdraw their deposits, and the bank's managers liquidate its loans, if they get the unfavorable signal about the bank. At the end of the period, the banks pay out returns to the depositors.

At the beginning of period 2, the new depositors of both banks observe the returns received by the depositors of the banks, last period, along with the diversification regime that was chosen by those banks' managers. The new depositors then make their manager replacement decisions. Each bank's depositors make the decision (retain or replace) that maximizes the expected utility of their returns. These decisions are influenced by the depositors' knowledge of whether and 
how much the managers of the two banks will choose to diversify the banks' loan portfolios under different scenarios involving their competence and experience. The events of the rest of the period proceed as in period 1, except that there are no government-imposed constraints on the managers' diversification decisions - whether or not there such constraints, in period 1 - and the economy ends at the end of the period.

The key difference between period 1 and period 2 is that, in period 2, one bank may have experienced managers while the other bank has inexperienced managers, or both banks may have inexperienced managers. (Assuming, as we continue to do, that if the depositors know that one set of incumbent managers is incompetent, but do not know which one, then they replace both sets.)

\section{G. Interpretations and Assumptions}

As we explained in our introduction, the motivation for our analysis involves, in large part, some widely held beliefs about the length and severity of economic recessions. So we need to identify the outcomes, in our model, that represent recessions. Since loan returns are the only output in the model, we think of the total loan return in a period, across the portfolios of the two banks, as the "total output" for the period.

For our purposes, periods in which one of the base loan return outcomes is bad are "recession" periods. In these periods, the total loan return is significantly below average, and one of the banks has made bad lending decisions. ${ }^{15}$ Thus, in this model, the cause of recessions is bad lending decisions by banks. (It should be noted, however, that when there are two low shocks, good lending decisions by both banks can produce a total loan return that is lower than the total return in some recessions.) Recessions vary in severity, because of the shocks to the base return outcomes. They also vary in severity across diversification regimes, because diversification produces inefficient liquidation decisions. Whenever a diversified portfolio is liquidated, during a recession, some loans that would have yielded a total return in excess of the liquidation value are liquidated, reducing output. And whenever a diversified portfolio is not liquidated, during a recession, some loans that will yield a total return below the liquidation value are not liquidated: again, output is reduced.

We think of periods in which at least one bank liquidates its asset portfolio ("fails") as periods of "financial crisis." A financial crisis can occur only when there is a recession. When the banks diversify their asset portfolios, however, a recession may not always produce a financial crisis.

\footnotetext{
${ }^{15}$ A bank whose portfolio includes loans whose base returns are bad may or may not actually receive the returns on those loans, because it may liquidate its portfolio. But we say a recession has occurred whenever the base returns on the loans originated by one of the two banks are bad, whether or not either bank receives those returns.
} 
If both banks liquidate their asset portfolios then we say the financial crisis is "systemic." The resulting total loan return is lower than any other total return that can occur in the model. So periods in which double-liquidation occurs are also called periods of "severe recession." As we have seen, systemic crises and severe recessions can occur only when the banks' portfolios are diversified. This feature of the model is a consequence of our assumption that, in any period, if both sets of bank managers are ex ante competent (so that they made good loans last period, or are they new to bank management), at most one set of loans turns out to be bad. This assumption is made largely for analytical clarity. We have structured the model so that systemic crises may be caused by bank interconnectedness, and this assumption prevents us from having to distinguish systemic crises caused by interconnectedness from systemic crises that might have occurred without it.

The sequential structure of the model introduces an exogenous "business cycle" of a very simple type. On average, output in period 1 is higher than in period 2. The reason for this is that the economy begins, in period 1, with two sets of experienced bank managers, so that the probability of a recession is relatively low. ${ }^{16}$ However, a recession in period 1 always increases the probability of a recession in period 2: it indicates that one set of bank managers was incompetent, leading to the replacement of one or both sets of managers.

When the banks' portfolios are diversified, in period 1, the effect of a period-1 recession on the probability of a period-2 recession is magnified, because some recessions cause both sets of managers to be replaced. The increased probability of a period-2 recession also increases the probability of a systemic crisis, which produces the most severe type of recession. Thus, in our model, interconnectedness among banks increases the frequency of recessions in period 2 , the average severity of recessions in both periods, and the average length of recessions (that is, the probability of consecutive recessions).

In our business cycle interpretation, period 1 is a period when the economic outlook is relatively favorable, but also a period in which problems can occur that will make the outlook, next period, much less favorable. The government's goal, as we shall see, is to regulate the banking system during the period when the outlook is favorable in order to make the economy's prospects in the following period less unfavorable, increasing depositors' average expected utility across the two periods.

\footnotetext{
${ }^{16}$ In a multi-period version of the model, the unconditional probability of entering a period with two experienced managers would be higher than the other possibilities, so there would still be a type of business cycle. But such a version would be more difficult to analyze, partly because the government might have an incentive to regulate interconnectedness even when one or fewer sets of managers was experienced.
} 


\section{H. Summary of the Baseline Example}

A more detailed description of this example is presented in appendix B. Here, we summarize some of its important properties. These properties are determined by using the parameters from the example to obtain the marginal and joint return distributions for each of the three possible numbers of experienced managers (two, one or zero) and each of the three possible diversification regimes. We can then determine the structure of the equilibrium return-outcomes distribution, across both periods, if there is no government regulation, and we can determine which diversification regime the government will impose, in period 1, if there is regulation. We can also calculate various summary measures of this outcomes distribution. As we have seen, the nature of the distributions, and thus, the values of the summary measures, may depend on depositors' degree of risk aversion, which influences both the diversification decisions of the banks' managers and the regulation decisions of the government.

\section{Specification}

As we have seen, the two versions of the example differ only in that, in the first version, there are no random shocks to the bad base return. The good base loan return outcome is 1 and the bad outcome is $1 / 2$. The shock to the good base return is $\pm 1 / 3$, and, in Version 2 , the shock to the bad return is $\pm 1 / 12$. The liquidation value is $5 / 8$.

If a bank's managers are experienced, the probability they will be competent is $3 / 4$; if they are inexperienced, it falls to $1 / 2$. If one bank's managers are experienced and the other bank's managers are inexperienced, then in the event of a mixed outcome there is a $2 / 3$ probability that the experienced managers will be the ones who originated the good loans. Given our assumption that at least one set of managers always originates good loans, unless one or both sets made bad loans, last period (which does not happen, in equilibrium), it follows that if both sets of bank managers are experienced, the probability they will both originate good loans is $1 / 2$. This probability falls to $1 / 4$ if one set of managers is inexperienced, and to 0 if both sets are inexperienced.

Finally, under partial diversification, one-third of each bank's asset portfolio consists of loans originated by the other bank.

Clearly, the magnitude of certain important features of the model has been exaggerated to make it easier to identify their roles. The probability of a recession in period 1 , which is entirely exogenous, has been set very high: 50 percent. And our assumptions imply that the output loss from a recession is always on the order of 20 percent of non-recession output. These features tends to increase the benefits from government intervention to limit diversification, which, as we shall see, can reduce the frequency of recessions and, to a lesser extent, their output costs. On the other hand, the variation in the base returns is very large: the bad return is only half the size 
of the good return. And the shocks around the base returns are also quite large. The shock to the good base return is one-third as large as that return. And, in Version 2, where there are shocks to the bad base return, these shocks are a sixth as large as that return. These features tend to increase the costs of government intervention to limit diversification, since they create the possibility of large welfare gains from risk spreading.

\section{Laissez, Faire (LF) Equilibria}

In the absence of government regulation, the diversification regime chosen by the banks' managers in period 1 is CD, regardless of depositors' degree of risk aversion. The welfare benefits from risk spreading trump the costs from inefficient liquidation (see below), even when the depositors are only weakly risk averse.

In period 1, expected output per depositor in period 1 is 11.5 percent below "normal" (expected non-recession) output per depositor, which is unity. (We will drop "per depositor" henceforth.) There is a 50 percent probability of a recession, and output averages 22.9 percent below normal during a recession. Half the recessions are accompanied by financial crises (liquidation by a bank); all these crises are systemic (involve both banks). Some recessions are not accompanied by financial crises because favorable shocks allow the banks' common portfolio return to remain above below the liquidation value, even though one set of loans is bad. All liquidations involve systemic crises because, under $\mathrm{CD}$, the two banks' returns are always equal.

Although liquidation does not occur in all recessions, all recessions feature inefficient liquidation decisions. In half the recessions, loans whose return outcomes are below $q$ are not liquidated; in the other half, loans whose return outcomes would have been below $q$ are liquidated. The inefficient liquidation makes the average output loss in a recession, and, thus, the average output loss from recessions, substantially higher than they would be otherwise: see below.

In period 2, there is a 50 percent probability that the return outlook will be identical to the outlook in period 1, because the depositors of both banks will retain the banks' managers, so that both sets of managers will remain experienced. These events follow an unmixed joint return outcome in period 1. But there is also 50 percent probability that the depositors of both banks will replace the banks' managers. This probability is so high because, under CD, replacement of both banks' managers always follows an unmixed outcome in period 1: the two banks always pay the same return, so it is never possible to infer which bank's managers originated bad loans.

When both banks' managers are inexperienced, a recession always occurs. So the probability of a recession, in period 2, is 75 percent. Since half the recessions are accompanied by systemic crises, the probability of the latter rises from 25 percent in period 1 to 37.5 percent in period 2 . 
If the depositors are weakly risk averse, the effect of the higher probability of recession on expected output in period 2 is partly mitigated by the fact that if both banks' managers are inexperienced, they choose ND, so that there are no losses from inefficient liquidation (see below). Consequently, output in recession averages 20.1 percent less than normal, instead of 22.9 percent. Average output is in period 2 is 15.1 percent below normal output, compared to 11.5 percent in period 1 .

The fact that the average return is lower in period 2 reflects the "business cycle" built into the model: period 2 is inherently less favorable, on average, because there are always possible period-1 return outcomes that result in at least one bank having inexperienced managers next period. When depositors are moderately or strongly risk averse, the amplitude of the business cycle is exacerbated by the fact that the banks' managers choose CD (and with it, the possibility of inefficient liquidation) even when they are both inexperienced. In this case, output in recession again averages 22.9 percent below normal, and average output is 17.2 percent below normal output.

The probability of a long (two-period) recession is 50 percent. In this simple example, if there is no government regulation then a recession in period 1 is always followed by a recession in period 2 .

\section{Equilibria under Government Regulation}

If the government regulates the banking system, the results differ substantially across different degrees of depositor risk aversion, and moderately across different versions of the example.

If the depositors are weakly risk averse then the government imposes ND, in period 1 , in both versions of the example. It does so because the period-1 depositors are not hurt much by the increase in the variability of their returns that results from eliminating diversification. Consequently, their losses are outweighed by the benefits, to the period-2 depositors, of a sharply reduced probability of a recession in that period. (The period 1 depositors also benefit from elimination of liquidation inefficiency, though that benefit is not large enough to prevent then from being worse off, on net.)

In period 1, the probability of a recession does not change, but expected output is only 9.4 below normal output, because expected output in a recession is only 18.8 percent below normal. The difference between this figure and the LF figures of 11.5 and 22.9 percent reflect the inefficiency of liquidation when there is diversification. Under ND, every recession features liquidation by the bank whose managers originated the bad loans (a financial crisis). But all these loans are liquidated, and none of the other loans are, so liquidation is efficient. There is no possibility of liquidation by both banks (a systemic crisis). 
No diversification (ND) in period 1 improves the outlook for period 2 by replacing the 50 percent probability that both banks will have inexperienced managers with an equal probability that only one bank will have them. Now, it is easy for period-2 depositors to identify the bank whose managers originated bad loans: it is the bank whose portfolio was liquidated. So those managers are replaced, but not the others. And when only one bank has inexperienced managers, the probability of a recession is only 75 percent. So the probability of a long recession falls from 50 percent to 37.5 percent, because a recession in period 1 no longer guarantees a recession in the next period.

Thus, government regulation loosens the otherwise-tight link between recessions in period 1 and recessions in period 2, and it causes the unconditional probability of a recession in period 2 to fall to 62.5 percent.

The fact that the government chooses ND in period 1, in this case, allows us to use it to help identify the various disadvantages of diversification for the model economy. As we have seen, under ND, in period 1, the average output loss from recessions is only 9.4 percent, compared to 11.5 percent under LF. More importantly, however, the probability of a recession in period 2 is only 62.5 percent, compared to 75 percent under LF.

We can identify additional disadvantages of diversification by imagining what would happen if it was also prohibited in period 2. The average output loss from recessions would be 11.7 percent, in that period, compared to the LF figures of 15.1 or 17.2 percent, depending on depositors' degree of risk aversion. These differences reflect both the lower probability of recessions and the elimination of inefficient liquidation. Notice that, not only is the average output loss from recessions much lower in period 2, absent diversification, it also rises less steeply from period 1 to period 2 - increasing by only 2.3 percentage points, compared to 3.6 or 5.7 percentage points under LF. The probability of a long recession is 37.5 percent, as above: as we have seen, when there is ND in period 1 the depositors choose ND in period 2 even if they have other options.

Returning to the question of the impact of government regulation when depositors are weakly risk averse, it turns out that, in this case, experienced managers will not diversify their loan portfolios with loans made by inexperienced managers. So diversification (CD) will occur, in period 2, only when there was no recession in period 1. Average output in recession is only 20.4 percent below normal, because three-fifths of the recessions do not result in inefficient liquidation. So the average level of output is only 12.8 percent below normal, compared to 15.1 percent without regulation.

Thus, when depositors are weakly risk averse, government regulation reduces both the average output cost from recessions and the average amplitude of the business cycle, though not by quite as much as they would be reduced if diversification was not possible. (It's worth emphasizing, however, that eliminating diversification would reduce the welfare of both groups of depositors, 
even in this case.) And it reduces the probability of a long recession, by exactly as much ( 25 percent) as it would be reduced if diversification was not possible.

If the depositors are moderately or strongly risk averse then the government restricts but does not prohibit diversification, allowing the bank managers to choose PD but not CD. Here, the benefits of diversification to the period-1 depositors are too great for the government to ignore. And it can reduce the probability of recession, in period 2, by restricting diversification, though not to the same extent as by prohibiting it.

Limiting diversification in period 1 is less effective, at preventing recessions, than prohibiting diversification, because it does not rule out the worst-case scenario for period 2 - replacement of both banks' managers. However, recessions in period 2 remain less likely than under LF because replacement of both banks' managers now occurs only if there is a systemic crisis in period 1 - that is, only if both banks liquidate their portfolios. If there is no financial crisis, or if there is a non-systemic crisis (which can happen under PD, and does happen in Version 2), the period-2 depositors can use the differences in the returns the period-1 depositors were paid to infer which bank's managers originated the bad loans. (Under CD, there are never any such differences, whether or not the bank portfolios are liquidated.) In these cases, only one bank has inexperienced managers in period 2 - the same situation that follows recessions when the period1 regime is ND.

As under LF/CD, half the recessions produce liquidation by at least one bank: a financial crisis. In Version 1, all these crises are systemic: both banks liquidate, as under LF/CD. In Version 2, however, half the crises involve liquidation by only one bank, so that only a fourth of the recessions produce systemic crises.

While there is the usual one chance in two that both banks will have experienced managers in period 2, in Version 1 there is one chance in four that only one bank will have inexperienced managers - a possibility that does not exist under LF - and one chance in four that both will have them - a possibility that does not exist when the government regulates the banks but the depositors are less risk averse. In Version 2, these figures are three chances in eight and one in eight, respectively. Consequently, in Version 1, the probability of a recession in period 2 is 11/16 (almost 0.69 ), compared to 0.625 when the depositors are weakly risk averse, and compared to 0.75 under LF. In Version 2, the period-2 recession probability is $21 / 32$ (a bit more that 0.65 ). The probability of a long recession is $7 / 16$ (almost 0.44 ) in Version 1 and 13/32 (less than 0.41 ) in Version 2. So regulation continues to reduce the risk of long recessions substantially.

Thus, when the depositors are relatively risk averse, the relatively moderate form of regulation chosen by the government does not loosen the link between period- 1 and period- 2 recessions as much as it is loosened by the extreme form of regulation the government chooses when depositors are less risk averse. However, this more moderate form of regulation creates a tight 
link between systemic crises in period 1 and recessions in period 2. Under LF (CD in period 1), all recessions in period 1 are followed by recessions in period 2: there is nothing special about recessions that produce systemic crises. And under extreme regulation (ND in period 1), there are no systemic crises in period 1. Under moderate regulation (PD in period 1), however, there are still systemic crises in period 1 (although in Version 2, they are less common than before), and recessions that involve systemic crises are the only ones that are invariably followed by recessions next period.

In Version 1, the average period-1 recession reduces output by 22.9 percent, exactly as under LF. So output averages 11.5 percent below normal. In Version 2, the figures are 23.6 percent and 11.8 percent, respectively. These figures are not very different from LF because the extent of the inefficient liquidation is not very different under PD than under CD.

In period 2, both the extent to which the average recession reduces output and the average output cost of recessions depends both on the depositors' degree of risk aversion and the version of the example. They increase as depositors get more risk averse, because there is more diversification and, thus, more inefficient liquidation. They decrease in Version 2, relative to Version 1, because in Version 2 the worst-case scenario for period 2 is less likely. The lowest figures are 21.1 percent and 13.8 percent, for depositors who are moderately risk averse and Version 2; the highest figures are 22.9 percent and 15.8 percent, for depositors who are strongly risk averse and Version 1. But even the latter figure remains substantially lower than 17.2 percent, which is the average output loss from recessions, for these degrees of risk aversion, when there is no regulation.

Thus, government regulation also moderates the business cycle, and reduces the frequency of long recessions, when depositors are relatively risk averse.

\section{CONCLUSIONS}

The goal of our analysis has been to construct a simple theoretical model that helps explain the relationship between interconnectedness of financial institutions, systemic financial crises, and long, severe recessions.

In our model, banks connect with each other by loan portfolio diversification: their portfolios include loans originated by other banks.

This sort of interconnectedness is attractive to bank depositors but potentially hazardous for the banking system. 
The model's key assumptions are that

- Recessions occur because banks make bad loans, and banks make bad loans because their managers are incompetent at risk assessment.

- Loan portfolio diversification makes it difficult for a bank's depositors to determine the returns on particular components (by originator) of the bank loan portfolio.

As a result, depositors may make inefficient decisions, of two types:

- Decisions about loan liquidation, and

- Decisions about retention or replacement of bank managers.

Inefficient loan liquidation decisions may increase the severity of recessions; they may also produce systemic financial crises.

Systemic crises, in turn, help create situations in which depositors make inefficient manager replacement decisions.

Inefficient replacement decisions reduce the ability of the banking system to assess credit risk, increasing the probability of long, severe recessions.

Government restrictions on interconnectedness can increase the average welfare of bank depositors.

However, the optimal degree of restriction may not entirely prevent systemic financial crises or long, severe recessions. 


\section{REFERENCES}

Allen, Franklin and Douglas Gale. 2000. "Financial Contagion." Journal of Political Economy 108:1, pp. 1-33.

Bernanke, Benjamin. 2007. "The Financial Accelerator and the Credit Channel." Address at the Federal Reserve Bank of Atlanta's Conference on the Credit Channel of Monetary Policy in the $21^{\text {st }}$ Century. Board of Governors of the Federal Reserve System, June.

Bimpikis, Kostas and Alireza Tahbaz-Salehiz. 2012. "Inefficient Diversification.” Working paper, October.

Boissy, Frederic, Fabrice Collard and Frank Smets. 2013. "Booms and Systemic Banking Crises." Working paper, January.

Gambacorta, Leonardo and Adrian van Rixtel. 2013. "Structural Bank Regulation Initiatives: Approaches and Implications, BIS Working Paper No. 412, Bank for International Settlements, April.

Greenwood, Jeremy and Boyan Jovanovic. 1990. "Financial Development, Growth, and the Distribution of Income." Journal of Political Economy 98:5, pp. 1076-1107.

Ibragimov, Rustam, Dwight Jaffee and Johan Walden. 2011. "Diversification Disasters." Journal of Financial Economics 99 (September), pp. 333-348.

Jordá, Oscar, Moritz Schularick and Alan M. Taylor. 2014. "The Great Mortgaging: Housing Finance, Crises, and Business Cycles." Working paper, Federal Reserve Bank of San Francisco.

Kannan, Prakash, Alasdair Scott, and Marco E. Terrones. 2009. "From Recession to Recovery: How Soon and How Strong." World Economic Outlook, International Monetary Fund, April.

The Financial Crisis Inquiry Commission. 2011. "The Financial Crisis Inquiry Report." National Commission on the Causes of the Financial and Economic Crisis of the United States. U.S. Government Printing Office, February.

Reinhart, Carmen M. and Kenneth S. Rogoff. 2009. "The Aftermath of Financial Crises." American Economic Review 99:2 (May), pp. 466-472. 
Wagner, Wolf. 2010. "Diversification at Financial Institutions and Systemic Crises." Journal of Financial Intermediation 19 (July), pp. 373-386.

. 2011. "Systemic Liquidation Risk and the Diversity-Diversification TradeOff. Journal of Finance LXVI:4 (August), pp. 1141-1175. 


\section{APPENDIX A: TWO ISSUES}

\section{Is the Nash equilibrium involving replacement of both set of bank managers unique?}

To show that this equilibrium is unique, we need to show that if Bank B's depositors choose not to replace its managers, then it remains optimal for Bank A's depositors to replace its managers. If Bank B does not replace its managers, and Bank A chooses to replace its managers (so that they inexperienced), then there are two possibilities. One is that Bank B's managers are incompetent. In this case, Bank A's managers will not choose to diversify with Bank B, and Bank A's depositors will get the expected utility from the inexperienced undiversified return distribution (eu-i). The other possibility is that Bank B's managers are experienced. In that case, if Bank A gets $e u-i e$, the expected utility of the return distribution received by a bank with inexperienced managers, when the other bank has experienced managers. Note that the nature of this distribution depends on whether a bank with experienced managers chooses to diversify with a bank with inexperienced managers, and how much.

If neither bank replaces its managers, then there are, again, two possibilities. If Bank B's managers are incompetent, then Bank A's managers are experienced. They will not diversify with Bank B, and the Bank A's depositors will get the expected utility from the experienced undiversified return, eu-e. If Bank B's managers are experienced, then Bank A's managers are incompetent, and Bank A gets expected utility eu- $n$.

For a given level of intensity of depositor risk aversion, if the average of eu-i and $e u$-ie, given the degree of diversification chosen by the experienced managers, exceeds the average of $e u-e$ and $e u-n$, then there is no Nash equilibrium with double non-replacement. Moreover, if there is a Nash equilibrium with double replacement, then there cannot be a Nash equilibrium in which one bank replaces it managers and the other does not. So the Nash equilibrium with double replacement is unique. (Again, this is true in both versions of our baseline example.)

\section{Is the assumption that bank depositors live for only one period, while the government cares about depositors in both periods, essential for our results?}

In this section of the appendix, we outline slightly more complicated assumptions under which there is a single set bank depositors that lives during and cares about deposit returns earned during each period.

As before, we assume there is a of depositors at the beginning of period 1, and that these depositors are divided into two equal-measure groups by location. Now, however, each depositor lives during both periods. Each period, each depositor may make his deposit at any of a continuum of banks in his location. In period 2, a depositor may choose to make his second 
deposit at the same bank he patronized in period 1, or at a different bank in his location. The loans originated by each bank in his location will yield the same return. In principle, however, different banks may make different diversification decisions.

A bank that does not receive deposits in period 1 closes down, and is not available to accept deposits in period 2 .

Consider the problem facing a representative depositor, in period 1, who is confronted by some banks whose managers announce that that they will diversify completely, and others who announce that they will limit their diversification. In our baseline example, complete diversification produces the most favorable return pattern for the depositor, in period 1, while limited diversification, of some sort, produces the most favorable return pattern across the two periods. Since this depositor is not tied to the bank she chooses, next period, she has no incentive to choose a bank that limits diversification. She is one of a continuum of depositors, and her individual decision does not influence the options available to her next period. She will choose a bank that diversifies completely, expecting to be able to switch banks, next period. If other depositors are concerned about the future implications of complete diversification, they will choose banks that limit diversification, giving her attractive banks to switch to.

In equilibrium, however, all the depositors will choose banks that diversify completely, and the only banks available to depositors, next period, will be banks that diversified completely last period.

The government, however, can intervene, to improve matters, by restricting diversification. In this version of the model, what the government can do, that the depositors can't, is impose coordination on the depositors. Without the government, if a group of depositors tries to get together, in period 1, to support a bank that limits diversification, each individual in the group has an incentive to defect to a bank that offers a more favorable (completely diversified) return distribution, this period, secure in the knowledge that she can "return to the fold," next period.

It's worth noting that this argument is reminiscent of a widely-held view about a source of instability in our financial system. According to this view, banks have an incentive to chase "hot money," offering high interest rates to large, short-term depositors. Banks that don't do this can't attract such depositors, which places them at a competitive disadvantage. But the need to earn loan returns high enough to justify these high deposit rates forces the banks to take too much risk, endangering their future solvency. The large, short-term depositors are unconcerned about this situation, because they believe, correctly, that they can withdraw their deposits before the banks get in serious trouble. Ultimately, however, their actions help generate a financial crisis, the result of which is a severe recession during which high interest rates are no longer available to anyone. The government can intervene to solve the problem, or, at least, to reduce its severity, by regulating the banking system to prevent it from taking excessive risks. 
In our model, the loan return distribution is essentially exogenous, and the only way banks can differ from each other is in their degrees of diversification. But, according to the argument we have just developed, competitive pressure forces banks to choose a degree of diversification that is too "risky," in the sense of making the banking system vulnerable to a severe financial crises, and making the economy more vulnerable to long, severe recessions. And the government can ameliorate the problem by regulating the banking system to limit diversification. 


\section{APPENDIX B: THE BASELINE NUMERICAL EXAMPLE}

In Version 1 of the example, there are random shocks only to good base returns. Since $\varepsilon^{b}=0$, in this version, we drop the subscript on $\varepsilon^{g}$ when we describe it. In Version 2, there are also shocks to bad base returns, with $\varepsilon^{b}=\frac{1}{12}$. In both versions, as we have seen, we have $g=1$, $\varepsilon^{g}=\frac{1}{3}, b=1 / 2, q=\frac{5}{8}$, and $\theta_{2}=\frac{1}{3}$. The probability structure is $p^{e}=\frac{3}{4}, p^{i}=\frac{1}{2}$, and $p^{m e}=\frac{2}{3}$, so that $p^{e e}=\frac{1}{2}, p^{e i}=\frac{1}{4}$, and $p^{i i}=0$.

\section{Period 1: Return outcomes and implications, by diversification regime}

\section{No diversification [ND]}

In this case $(\theta=0)$, each bank's depositors get the return on the loans originated by that bank.

The joint potential portfolio return outcomes $\{A, B\}$ for period 1 (when the managers of both banks are experienced) are

Version 1: $\left\{\begin{array}{l}\left\{\frac{4}{3}, \frac{4}{3}\right\},\left\{\frac{4}{3}, \frac{2}{3}\right\},\left\{\frac{2}{3}, \frac{4}{3}\right\},\left\{\frac{2}{3}, \frac{2}{3}\right\} \\ \left\{\frac{4}{3}, \frac{1}{2}\right\},\left\{\frac{2}{3}, \frac{1}{2}\right\}, \\ \left\{\frac{1}{2}, \frac{4}{3}\right\},\left\{\frac{1}{2}, \frac{2}{3}\right\}\end{array}\right\} \quad$ Version 2: $\left\{\begin{array}{l}\left.\left\{\frac{4}{3}, \frac{4}{3}\right\},\left\{\frac{7}{3}\right\}, \frac{2}{3}\right\},\left\{\frac{4}{3}, \frac{5}{12}\right\},\left\{\frac{4}{3}, \frac{7}{12}\right\},\left\{\frac{2}{3}, \frac{2}{3}\right\} \\ \left.\left\{\frac{7}{12}, \frac{4}{3}\right\},\left\{\frac{7}{12}\right\}, \frac{4}{3}\right\},\left\{\frac{5}{12}, \frac{4}{3}\right\},\left\{\frac{5}{12}, \frac{2}{3}\right\}\end{array}\right\}$

The realized return outcomes are

Version 1: $\left\{\begin{array}{l}\left\{\frac{4}{3}, \frac{4}{3}\right\},\left\{\frac{4}{3}, \frac{2}{3}\right\},\left\{\frac{2}{3}, \frac{4}{3}\right\},\left\{\frac{2}{3}, \frac{2}{3}\right\} \\ \left\{\frac{4}{3}\right\},\left\{\frac{5}{3}, \frac{5}{8}\right\}, \\ \left\{\frac{5}{8}, \frac{4}{3}\right\},\left\{\frac{5}{8}, \frac{2}{3}\right\}\end{array}\right\} \quad$ Version 2: $\left\{\begin{array}{l}\left\{\frac{4}{3}, \frac{4}{3}\right\},\left\{\frac{4}{3}, \frac{2}{3}\right\},\left\{\frac{5}{3}, \frac{4}{3}\right\},\left\{\frac{4}{3}, \frac{5}{8}\right\},\left\{\frac{2}{3}, \frac{5}{8}\right\},\left\{\frac{2}{3}, \frac{5}{8}\right\} \\ \left\{\frac{5}{8}, \frac{4}{3}\right\},\left\{\frac{5}{8}, \frac{2}{3}\right\},\left\{\frac{5}{8}, \frac{4}{3}\right\},\left\{\frac{5}{8}, \frac{2}{3}\right\}\end{array}\right\}$

because when the potential return outcome on the loan's in a bank's portfolio is lower than $q$, the bank receives information that causes it to liquidate the portfolio. Note that, in version 2, the realized joint return distribution also has only eight distinct outcomes.

For example, in version 1, a mixed outcome favoring Bank B, with a low shock to the good base return, is potentially $\{A, B\}=\{b, g-\varepsilon\}=\left\{\frac{1}{2}, 1-\frac{1}{3}\right\}=\left\{\frac{1}{2}, \frac{2}{3}\right\}$, but actually $\{A, B\}=\{q, g-\varepsilon\}=$ $\left\{\frac{5}{8}, \frac{2}{3}\right\}$, because $b<q$, which is $\frac{1}{2}<\frac{5}{8}$. In version 2 , a mixed outcome of the same type, with a high shock to the low base return, is potentially $\{A, B\}=\left\{b+\varepsilon^{b}, g-\varepsilon^{g}\right\}=\left\{\frac{1}{2}+\frac{1}{12}, 1-\frac{1}{3}\right\}=\left\{\frac{7}{12}, \frac{2}{3}\right\}$, but in reality $\{A, B\}=\{q, g-\varepsilon\}=\left\{\frac{5}{8}, \frac{2}{3}\right\}$, because $b+\varepsilon^{b}<q$, which is $\frac{1}{2}<\frac{5}{8}$. 
When both banks have experienced managers, which is the situation in period 1 , the eight distinct joint realized return outcomes are equally likely. In this case, the marginal realized return distribution for either bank is

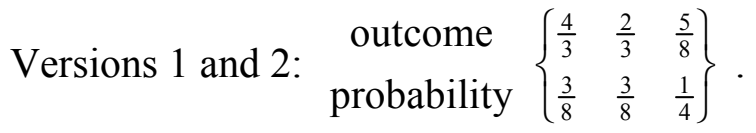

We call this return distribution ee-nd. Its expected utility is denoted $E U_{s}(e e-n d)$, where $s=1,2,3$ represents the intensity of risk aversion, from lowest $(\gamma=1)$ to highest $(\gamma=4)$.

The probability that both banks will have experienced managers in period 2 is $1 / 2$, the probability of an unmixed return outcome. If the joint return outcome in period 1 is mixed, it is clear, from the portfolio returns, which bank originated the bad loans: it is the bank whose return outcome is the liquidation return. Thus, the probability, in period 2, that one bank will have experienced managers and the other will have inexperienced managers is also $1 / 2$, and the probability that both banks will have inexperienced managers is zero.

\section{Partial diversification [PD]}

In this case $\left(\theta=\frac{1}{3}\right)$, two-thirds of each bank's portfolio consists of loans the bank's managers originated, and one-third consists of the loans originated by the managers of the other bank.

The joint potential portfolio return outcomes $\{A, B\}$ for period 1 are

Version 1: $\left\{\begin{array}{l}\left\{\frac{4}{3}, \frac{4}{3}\right\},\left\{\frac{10}{9}, \frac{8}{9}\right\},\left\{\frac{7}{9}, \frac{10}{9}\right\},\left\{\frac{11}{18}, \frac{5}{9}\right\}, \\ \left\{\frac{7}{9}, \frac{19}{18}\right\},\left\{\frac{5}{9}, \frac{11}{18}\right\}\end{array}\right\} \quad$ Version 2: $\left\{\begin{array}{l}\left\{\frac{4}{3}, \frac{4}{3}\right\},\left\{\frac{10}{12}, \frac{5}{6}\right\},\left\{\frac{37}{16}, \frac{13}{18}\right\},\left\{\frac{8}{36}, \frac{10}{9}\right\},\left\{\frac{2}{3}, \frac{2}{3}\right\},\left\{\frac{7}{12}, \frac{1}{2}\right\} \\ \left\{\frac{5}{6}, \frac{13}{12}\right\},\left\{\frac{13}{18}, \frac{37}{16}\right\},\left\{\frac{5}{8}, \frac{23}{36}\right\},\left\{\frac{1}{2}, \frac{7}{12}\right\}\end{array}\right\}$

The realized return outcomes are

Version 1: $\left\{\begin{array}{l}\left\{\frac{4}{3}, \frac{4}{3}\right\},\left\{\frac{10}{9}, \frac{8}{9}\right\},\left\{\frac{8}{9}, \frac{10}{9}\right\},\left\{\frac{2}{3}, \frac{2}{3}\right\} \\ \left\{\frac{7}{9}, \frac{19}{18}\right\},\left\{\frac{5}{8}, \frac{5}{8}\right\},\end{array}\right\} \quad$ Version 2: $\left\{\begin{array}{l}\left\{\frac{5}{3}, \frac{4}{3}\right\},\left\{\frac{10}{12}, \frac{5}{6}\right\},\left\{\frac{37}{36}, \frac{13}{18}\right\},\left\{\frac{23}{36}, \frac{5}{8}\right\},\left\{\frac{5}{8}, \frac{5}{8}\right\} \\ \left\{\frac{5}{6}, \frac{13}{12}\right\},\left\{\frac{13}{18}, \frac{37}{36}\right\},\left\{\frac{5}{8}, \frac{23}{36}\right\},\left\{\frac{5}{8}, \frac{5}{8}\right\}\end{array}\right\}$

In this case, in version 1, liquidation of both portfolios occurs whenever a mixed outcome features a low shock to the good base return. In version 2, it occurs only when the low shock to the good base return is accompanied by a low shock to the bad base return. 
For example, in version 1 a mixed outcome favoring Bank A, with a high shock to the good base return, is

$$
\{A, B\}=\{(1-\theta)(g+\varepsilon)+\theta b,(1-\theta) b+\theta(g+\varepsilon)\}=\left\{\frac{2}{3}\left(1+\frac{1}{3}\right)+\frac{1}{3}\left(\frac{1}{2}\right), \frac{2}{3}\left(\frac{1}{2}\right)+\frac{1}{3}\left(1+\frac{1}{3}\right)\right\}=\left\{\frac{19}{18}, \frac{7}{9}\right\} .
$$

In version 2 , the same type of outcome, with a low shock to the bad base return, is

$$
\begin{aligned}
\{A, B\} & =\left\{(1-\theta)\left(g+\varepsilon^{g}\right)+\theta\left(b-\varepsilon^{b}\right),(1-\theta)\left(b-\varepsilon^{b}\right)+\theta\left(g+\varepsilon^{g}\right)\right\} . \\
& =\left\{\frac{2}{3}\left(1+\frac{1}{3}\right)+\frac{1}{3}\left(\frac{1}{2}-\frac{1}{12}\right), \frac{2}{3}\left(\frac{1}{2}-\frac{1}{12}\right)+\frac{1}{3}\left(1+\frac{1}{3}\right)\right\}=\left\{\frac{37}{36}, \frac{13}{18}\right\}
\end{aligned}
$$

In version 1, when both banks have experienced managers, the eight outcomes are, again, equally likely. In version 2 , the four unmixed outcomes have collective probability $1 / 2$, and are equally likely, while the eight mixed outcomes (though only seven are distinct) also have collective probability $1 / 2$ and are also equally likely.

The realized marginal return distribution for either bank is

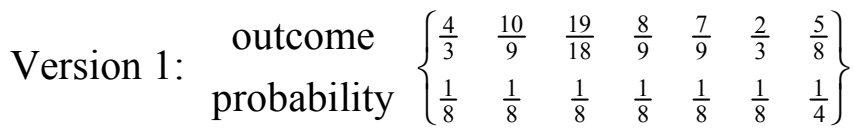

Version 2: $\begin{gathered}\text { outcome } \\ \text { probability }\end{gathered}\left\{\begin{array}{cccccccccc}\frac{4}{3} & \frac{10}{9} & \frac{13}{12} & \frac{37}{36} & \frac{8}{9} & \frac{5}{6} & \frac{13}{18} & \frac{2}{3} & \frac{23}{26} & \frac{5}{8} \\ \frac{1}{8} & \frac{1}{8} & \frac{1}{16} & \frac{1}{16} & \frac{1}{8} & \frac{1}{16} & \frac{1}{16} & \frac{1}{8} & \frac{1}{16} & \frac{3}{16}\end{array}\right\}$

We call these return distributions ee-pd. Their expected utility is denoted $E U_{s}(e e-p d)$, where $s=1,2,3$ represents the intensity of risk aversion, from lowest $(\gamma=1)$ to highest $(\gamma=4)$.

Again, the probability that both banks will have experienced managers in period 2 is $1 / 2$, the probability of an unmixed return outcome. If the joint return outcome in period 1 is mixed, and the two banks get different return outcomes, then the bank that originated the bad loans is the one with the lower portfolio return. Thus, in version 1, the probability, in period 2, that one bank will have experienced managers and the other will have inexperienced managers is also $1 / 4$. The probability that both banks will have inexperienced managers is also $1 / 4$, which is the probability that both banks liquidate their portfolios. Neither bank liquidates unless both do so. In version 2 , these probabilities are $3 / 8$ and $1 / 8$, respectively. For each bank, there is now probability $1 / 8$ it will fail, in period 1 , as part of a systemic financial crisis, and probability $1 / 16$ that it will be the only bank that fails. 


\section{Complete diversification $[\mathrm{CD}]$}

In this case $\left(\theta=\frac{1}{2}\right)$, each bank's portfolio is equally divided between loans the bank's managers originated, and loans originated by the managers of the other bank.

The joint potential portfolio return outcomes $\{A, B\}$ for period 1 are

Version 1: $\left\{\begin{array}{l}\left\{\frac{4}{3}, \frac{4}{3}\right\},\{1,1\},\{1,1\},\left\{\frac{2}{3}, \frac{2}{3}\right\} \\ \left\{\frac{11}{12}, \frac{11}{12}\right\},\left\{\frac{7}{12}, \frac{7}{12}\right\}, \\ \left\{\frac{7}{12}, \frac{7}{12}\right\},\left\{\frac{11}{12}, \frac{11}{12}\right\}\end{array}\right\} \quad$ Version 2: $\left\{\begin{array}{l}\left\{\frac{4}{3}, \frac{4}{3}\right\},\{1,1\},\{1,1\},\left\{\frac{2}{3}, \frac{2}{3}\right\} \\ \left\{\frac{23}{24}, \frac{23}{24}\right\},\left\{\frac{7}{8}, \frac{7}{8}\right\},\left\{\frac{5}{8}, \frac{5}{8}\right\},\left\{\frac{13}{24}, \frac{13}{24}\right\} \\ \left\{\frac{23}{24}, \frac{23}{24}\right\},\left\{\frac{5}{8}, \frac{5}{8}\right\},\left\{\frac{7}{8}, \frac{7}{8}\right\},\left\{\frac{13}{24}, \frac{13}{24}\right\}\end{array}\right\}$

The realized return outcomes are

Version 1: $\left\{\begin{array}{l}\left\{\frac{4}{3}, \frac{4}{3}\right\},\{1,1\},\{1,1\},\left\{\frac{2}{3}, \frac{2}{3}\right\} \\ \left\{\frac{11}{12}, \frac{11}{12}\right\},\left\{\frac{5}{8}, \frac{5}{8}\right\}, \\ \left\{\frac{5}{8}, \frac{5}{8}\right\},\left\{\frac{11}{12}, \frac{11}{12}\right\}\end{array}\right\} \quad$ Version 2: $\left\{\begin{array}{l}\left\{\frac{4}{3}, \frac{4}{3}\right\},\{1,1\},\{1,1\},\left\{\frac{23}{3}, \frac{2}{3}\right\} \\ \left\{\frac{23}{24}\right\},\left\{\frac{7}{8}, \frac{7}{8}\right\},\left\{\frac{5}{8}, \frac{5}{8}\right\},\left\{\frac{5}{8}, \frac{5}{8}\right\} \\ \left\{\frac{23}{24}, \frac{23}{24}\right\},\left\{\frac{5}{8}, \frac{5}{8}\right\},\left\{\frac{7}{8}, \frac{7}{8}\right\},\left\{\frac{5}{8}, \frac{5}{8}\right\}\end{array}\right\}$

In both versions, liquidation of both portfolios, or an equivalent joint return outcome, occurs whenever a mixed outcome features a low shock to the good base return.

For example, in both versions, an unmixed outcome, with a high shock Bank A's base return and a low shock to Bank B's, is

$$
\begin{aligned}
\{A, B\} & =\{(1-\theta)(g+\varepsilon)+\theta(g-\varepsilon),(1-\theta)(g-\varepsilon)+\theta(g+\varepsilon)\} . \\
& =\left\{\frac{1}{2}\left(1+\frac{1}{3}\right)+\frac{1}{2}\left(1-\frac{1}{3}\right), \frac{1}{2}\left(1-\frac{1}{3}\right)+\frac{1}{2}\left(1+\frac{1}{3}\right)\right\}=\{1,1\}
\end{aligned}
$$

When both banks have experienced manager, in version 1, the eight joint return outcomes (although only six are distinct) are again equally likely. And, again, in version 2 , the four mixed outcomes (but only three distinct) have collective probability $1 / 2$ and are equally likely, while the eight unmixed outcomes (but only three distinct) have collective probability $1 / 2$ and are equally likely.

The realized marginal return distribution for either bank is

Version 1: $\begin{gathered}\text { outcome } \\ \text { probability }\end{gathered}\left\{\begin{array}{ccccc}\frac{4}{3} & 1 & \frac{11}{12} & \frac{2}{3} & \frac{5}{8} \\ \frac{1}{8} & \frac{1}{4} & \frac{1}{4} & \frac{1}{8} & \frac{1}{4}\end{array}\right\} \quad$ Version 2: $\left\{\begin{array}{llllll}\frac{4}{3} & 1 & \frac{23}{24} & \frac{7}{8} & \frac{2}{3} & \frac{5}{8} \\ \frac{1}{8} & \frac{1}{4} & \frac{1}{8} & \frac{1}{8} & \frac{1}{8} & \frac{1}{4}\end{array}\right\}$

We call these return distributions $e e-c d$. Their expected utility is denoted $E U_{s}(e e-c d)$, where $s=1,2,3$ represents the intensity of risk aversion, from lowest $(\gamma=1)$ to highest $(\gamma=4)$. 
As usual, the probability that both banks will have experienced managers in period 2 is $1 / 2$, the probability of an unmixed return outcome. But the probability that both banks will have inexperienced managers is also $1 / 2$, so that the probability of the one bank will have experienced managers, and the other will have inexperienced managers, is 0 . Since the two banks always have identical portfolio returns, if there is a mixed return outcome then it is never possible to identify the bank whose mangers are at fault. And it follows that, in both versions, neither bank liquidates unless both do so.

\section{Period 2: Portfolio return distributions by experience of managers}

\section{Experienced-experienced}

When the managers of both banks are experienced, the return distributions are identical to those from period 1, when the same situation obtains. Since there is no rationale for government intervention in period 2, we assume the two banks choose the diversification regime that yields the highest expected utility for their depositors. In our baseline example, this regime turns out to be $\mathrm{CD}$, regardless of the version of the example or the depositors' intensity of risk aversion. So the return distribution is ee-cd and its expected utility is $E U_{s}(e e-c d), s=1,2,3$.

\section{Experienced-inexperienced, and vice-versa}

When one bank has experienced managers, we assume that the bank with experienced managers (Bank A, here) chooses the degree of diversification, since this bank has less to gain from diversification. The joint return outcomes are the same as for period 1, but their probabilities are different. The four unmixed outcomes have a collective probability of $1 / 4$. The two (version 1 ) or four (version 2) mixed outcomes favoring Bank A have collective probability $1 / 2$, while the two or four mixed outcomes favoring Bank B have collective probability $1 / 4$.

The marginal realized return distributions are

Bank A (experienced managers)

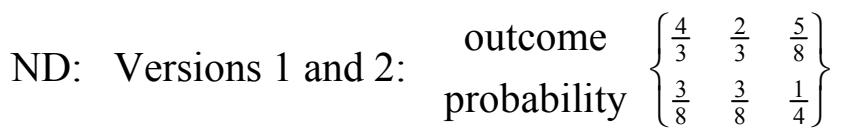

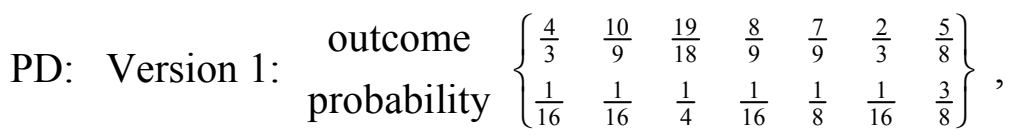

Version 2: $\begin{gathered}\text { outcome } \\ \text { probability }\end{gathered}\left\{\begin{array}{cccccccccc}\frac{4}{3} & \frac{10}{9} & \frac{13}{12} & \frac{37}{36} & \frac{8}{9} & \frac{5}{6} & \frac{13}{18} & \frac{2}{3} & \frac{23}{26} & \frac{5}{8} \\ \frac{1}{16} & \frac{1}{16} & \frac{1}{8} & \frac{1}{8} & \frac{1}{16} & \frac{1}{16} & \frac{1}{16} & \frac{1}{16} & \frac{1}{8} & \frac{1}{4}\end{array}\right\}$ 
CD: Version 1: $\begin{gathered}\text { outcome } \\ \text { probability }\end{gathered}\left\{\begin{array}{ccccc}\frac{4}{3} & 1 & \frac{11}{12} & \frac{2}{3} & \frac{5}{8} \\ \frac{1}{16} & \frac{1}{8} & \frac{3}{8} & \frac{1}{16} & \frac{3}{8}\end{array}\right\}$,

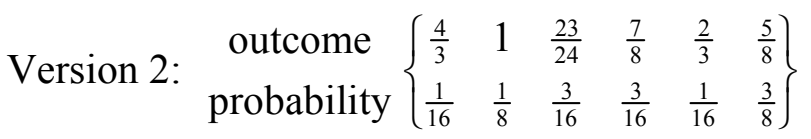

We call these return distributions $e i-n d, e i-p d$ and $e i-c d$, respectively, and their expected utilities $E U_{s}(e i-n d), E U_{s}(e i-p d)$ and $E U_{s}(e i-c d)$, respectively, $s=1,2,3$.

Bank B (inexperienced managers)

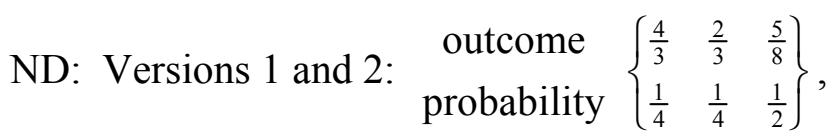

PD: Version 1: $\begin{gathered}\text { outcome } \\ \text { probability }\end{gathered}\left\{\begin{array}{ccccccc}\frac{4}{3} & \frac{10}{9} & \frac{19}{18} & \frac{8}{9} & \frac{7}{9} & \frac{2}{3} & \frac{5}{8} \\ \frac{1}{16} & \frac{1}{16} & \frac{1}{8} & \frac{1}{16} & \frac{1}{4} & \frac{1}{16} & \frac{3}{8}\end{array}\right\}$

Version 2: $\begin{gathered}\text { outcome } \\ \text { probability }\end{gathered}\left\{\begin{array}{cccccccccc}\frac{4}{3} & \frac{10}{9} & \frac{13}{12} & \frac{37}{36} & \frac{8}{9} & \frac{5}{6} & \frac{13}{18} & \frac{2}{3} & \frac{23}{26} & \frac{5}{8} \\ \frac{1}{16} & \frac{1}{16} & \frac{1}{16} & \frac{1}{16} & \frac{1}{16} & \frac{1}{8} & \frac{1}{8} & \frac{1}{16} & \frac{1}{16} & \frac{5}{16}\end{array}\right\}$

CD: Version 1: $\begin{gathered}\text { outcome } \\ \text { probability }\end{gathered}\left\{\begin{array}{ccccc}\frac{4}{3} & 1 & \frac{11}{12} & \frac{2}{3} & \frac{5}{8} \\ \frac{1}{16} & \frac{1}{8} & \frac{3}{8} & \frac{1}{16} & \frac{3}{8}\end{array}\right\}$

outcome
probability $\left\{\begin{array}{cccccc}\frac{4}{3} & 1 & \frac{23}{24} & \frac{7}{8} & \frac{2}{3} & \frac{5}{8} \\ \frac{1}{16} & \frac{1}{8} & \frac{3}{16} & \frac{3}{16} & \frac{1}{16} & \frac{3}{8}\end{array}\right\}$

We call these return distributions ie-nd, ie-pd and ie-cd, respectively, and their expected utilities $E U_{s}(i e-n d), E U_{s}(i e-p d)$ and $E U_{s}(i e-c d)$, respectively, $s=1,2,3$.

\section{Inexperienced-inexperienced}

When both banks have inexperienced managers, the four unmixed outcomes have a collective probability of 0 , and, thus, individual probabilities of 0 . The two (or four) mixed outcomes favoring Bank A have collective probability 1/2, as do the two (or four) mixed outcomes favoring Bank B.

The marginal realized return distributions are

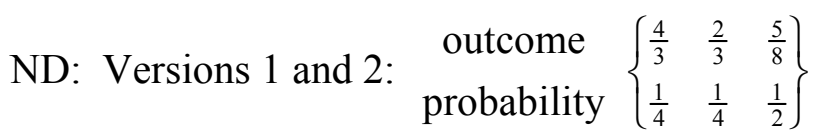




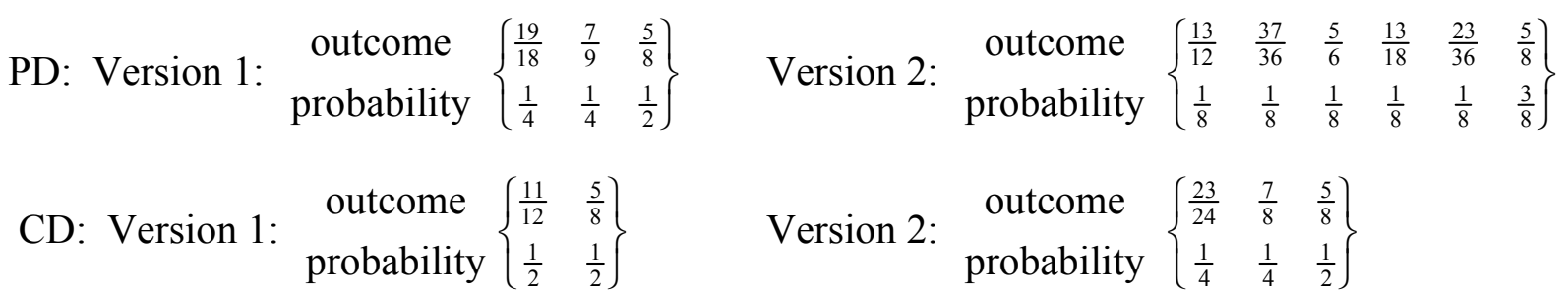

We call these return distributions $i i-n d$, $i i-p d$ and $i i-c d$, respectively, and their expected utilities $E U_{s}(i i-n d), E U_{s}(i i-p d)$ and $E U_{s}(i i-c d)$, respectively, $s=1,2,3$.

\section{Period 2: Diversification decisions}

As we have seen, when the managers of both banks are experienced, they choose the CD diversification regime in period 2, regardless of their intensity of risk aversion. They obtain the expected utility $E U_{s}(e e-c d), s=1,2,3$.

When the managers of one bank are experienced (Bank A), and the managers of the other bank (Bank B) are inexperienced, then the diversification regime the Bank A managers choose depends on their intensity of risk aversion. If it is weak or moderate then they choose not to diversify, as the decrease in the expected return outweighs the benefit from risk spreading. If it is strong, then they choose to diversify completely (CD), in the version 1 of the baseline example, or partially (PD), in version 2.

Thus, in the case of weak or moderate depositor risk aversion, the depositors of the bank with experienced managers get return distribution ei-nd and expected utility $E U_{s}(e i-n d), s=1$ or 2 . In the case of strong risk aversion, they get distribution $e i$-cd and expected utility $E U_{3}(e i-c d)$, in the simple version of the model, or $e i-p d$ and expected utility $E U_{3}(e i-p d)$, For the depositors of the bank with experienced managers, we simply replace $e i$ with $i e$. When we calculate the ex ante expected utility of a period- 2 depositor, we must average across the two relevant expected utilities, treating the depositor as unsure which bank he will be associated with.

When the managers of both banks are inexperienced, if their depositors are weakly risk averse then they choose not to diversify, because the potential losses from inefficient liquidation outweigh the benefits from risk spreading. (These losses are magnified because every return outcome includes a bad base return.) The depositors get return distribution ii-nd and expected utility $E U_{1}(i i-n d)$. Otherwise, they choose to diversify completely, so that their depositors get return distribution $i i-c d$ and expected utility $E U_{s}(i i-c d), s=2$ or 3 . 
It remains to verify that, in the case where there was a mixed joint return outcome in period 1, and the identity of the bank whose managers made the bad loans (and are thus incompetent) can't be determined, there is a unique symmetric Nash pure-strategies equilibrium in which both banks replace their managers.

\section{Period 2: The manager replacement decision when the identity of the "bad" managers is unknown}

As we have seen, to confirm that there is a pure-strategies Nash equilibrium in which the managers of both banks are replaced, we must start by calculating the expected utility received by a bank with inexperienced managers, when the managers of the other bank are also inexperienced. This value is $E U_{1}(i i-n d)$ or $E U_{s}(i i-c d), s=2$ or 3 . Next we calculate the expected utility received by a bank with incompetent managers, which we will denote $E U_{s}(n)$, $s=1,2$ or 3 : it is simply the expected utility of a return of $q\left(\frac{5}{8}\right)$ received with certainty. Finally, we calculate the expected utility received by a bank with experienced managers when the managers of the other bank are inexperienced, which is $E U_{s}(e i-n d), s=1$ or 2 , or $E U_{3}(e i-c d)$.

If $E U_{1}(i i-n d) \geq \frac{1}{2}\left\{E U_{1}(n)+E U_{1}(e i-n d)\right\}$, then we have our Nash equilibrium when $s=1$ (weak risk aversion).

If $E U_{2}(i i-c d) \geq \frac{1}{2}\left\{E U_{2}(n)+E U_{2}(e i-n d)\right\}$, then we have our Nash equilibrium when $s=2$ (moderate risk aversion).

If $E U_{3}(i i-c d) \geq \frac{1}{2}\left\{E U_{3}(n)+E U_{3}(e i-c d)\right\}$, in the version 1 of the baseline example, or $E U_{3}(i i-c d) \geq \frac{1}{2}\left\{E U_{3}(n)+E U_{3}(e i-p d)\right\}$, in version 2, then then we have our Nash equilibrium when $s=3$ (strong risk aversion).

It turns out that all three of these inequalities hold (strictly). So, in our baseline examples, there is always a Nash equilibrium in which the managers of both banks are replaced, regardless of depositors' intensity of risk aversion.

In order to prove that this pure-strategies Nash equilibrium is unique, we need to show that if one bank does not replace its managers then it is optimal for the other bank to replace its managers. As we have seen, if Bank B does not replace its managers, but Bank A does (so that its managers are inexperienced), then there are two possibilities. Bank B's managers may be incompetent, in which case Bank A's depositors get the inexperienced-undiversified return, with expected utility $E U_{s}(i i-n d), s=1,2$ or 3, or, Bank B's managers may be experienced, in which case Bank A's 
depositors get the inexperienced-experienced return, with expected utility $E U_{s}(i e-n d)$, $s=1$ or 2 , or $E U_{3}(i e-c d)$ [version 1], or $E U_{3}(i e-p d)$ [version 2].

If Bank A does not replace its managers, there are again two possibilities. Bank B's managers may be incompetent, in which case Bank A's managers are experienced. Its depositors will get the experienced-undiversified return distribution, with expected utility $E U_{s}(e e-n d), s=1,2$ or 3 - Alternatively, Bank B's managers may be experienced, in which case Bank A's are incompetent, and its depositors get expected utility $E U_{s}(n), s=1,2$ or 3 .

Thus, if $\frac{1}{2}\left\{E U_{s}(i i-n d)+E U_{s}(i e-n d)\right\} \geq \frac{1}{2}\left\{E U_{s}(e e-n d)+E U_{s}(n)\right\}$, then there is no Nash equilibrium in which both banks do not replace their managers, $s=1$ or 2 .

And if $\frac{1}{2}\left\{E U_{3}(i i-n d)+E U_{3}(i e-c d)\right\} \geq \frac{1}{2}\left\{E U_{3}(e e-n d)+E U_{3}(n)\right\}$ [version 1], or $\frac{1}{2}\left\{E U_{3}(i i-n d)+E U_{3}(i e-p d)\right\} \geq \frac{1}{2}\left\{E U_{3}(e e-n d)+E U_{3}(n)\right\}$ [version 2], then the same is true for $s=3$.

Again, all these inequalities hold, strictly, so, in our baseline example, there is no Nash equilibrium in which both sets of managers are retained. It follows, as we have seen, that the equilibrium in which both sets of managers are replaced, is unique.

\section{The unregulated equilibrium, and the welfare case for government regulation}

Is there a rationale for government intervention to prohibit or restrict interconnectedness in the first period?

We begin with the question of what the banks will do, in both periods, if they are not regulated.

In period 1, they will choose $\mathrm{CD}$, regardless of their depositors' intensity of risk aversion. In period 2 , there is probability $1 / 2$ that both banks have experienced managers, so that the situation from period 1 recurs, and the banks again choose complete diversification.

There is also probability $1 / 2$ that the managers of both banks are inexperienced. In this case, they do not diversify at all, if they are weakly risk averse, and they diversify completely, if they are moderately or strongly risk averse.

Again, the government's welfare criterion is the average ex ante expected utility of a depositor, across the two periods, assuming that, in each period, the depositor is equally likely to be a customer of either bank. So the value of this criterion is 


$$
\begin{aligned}
& \frac{1}{2}\left\{E U_{1}(e e-c d)+\frac{E U_{1}(e e-c d)+E U_{1}(i i-n d)}{2}\right\}, \text { for } s=1, \text { or } \\
& \frac{1}{2}\left\{E U_{s}(e e-c d)+\frac{E U_{s}(e e-c d)+E U_{s}(i i-c d)}{2}\right\}, \text { for } s=2 \text { or } 3 .
\end{aligned}
$$

In order to determine the government's optimal regulation decision, we also need to know the value of this welfare criterion if the banks choose ND or PD in period 1, perhaps because this choice is imposed on them, or perhaps as the best of a set of restricted choices

If they choose ND in period 1 , there is again a probability of $1 / 2$ that the return outcome will be unmixed, that they will both have experienced managers in period 2 , and that they will choose CD. And there is also a probability of $1 / 2$ that the return outcome will be mixed, in which case one of the two banks will have experienced managers, and the other will have inexperienced managers.

So the value of the government's welfare criterion is

$$
\begin{aligned}
& \frac{1}{2}\left\{E U_{s}(e e-n d)+\frac{E U_{s}(e e-c d)+\frac{1}{2}\left[E U_{s}(e i-n d)+E U_{s}(i e-n d)\right]}{2}\right\}, s=1 \text { or 2, or } \\
& \frac{1}{2}\left\{E U_{3}(e e-n d)+\frac{E U_{3}(e e-c d)+\frac{1}{2}\left[E U_{3}(e i-c d)+E U_{i}(i e-c d)\right]}{2}\right\}[\text { version 1] } \\
& \frac{1}{2}\left\{E U_{3}(e e-n d)+\frac{E U_{3}(e e-c d)+\frac{1}{2}\left[E U_{3}(e i-p d)+E U_{i}(i e-p d)\right]}{2}\right\}[\text { version 2], s=3. }
\end{aligned}
$$

If they choose PD, then in version 1 of our baseline example, there is a probability $1 / 2$ of a an unmixed outcome that produces two sets of experienced managers, probability $1 / 4$ of a mixed outcome that produced banks whose managers have different levels of experience, and there is probability $1 / 4$ of a mixed outcome that produces two sets of inexperienced managers. In version 2 , however, the probability that the banks will have managers with different levels of experience is $3 / 8$, and the probability that both banks will have inexperienced managers is $1 / 8$.

So in version 1 , the value of the government's welfare criterion is

$$
\begin{aligned}
& \frac{1}{2}\left\{E U_{1}(e e-p d)+\left[\frac{1}{2} E U_{1}(e e-c d)+\frac{1}{4}\left\{\frac{E U_{1}(e i-n d)+E U_{1}(i e-n d)}{2}\right\}+\frac{1}{4} E U_{1}(i i-n d)\right]\right\}, s=1, \\
& \frac{1}{2}\left\{E U_{2}(e e-p d)+\left[\frac{1}{2} E U_{2}(e e-c d)+\frac{1}{4}\left\{\frac{E U_{2}(e i-n d)+E U_{2}(i e-n d)}{2}\right\}+\frac{1}{4} E U_{2}(i i-c d)\right]\right\}, s=2, \\
& \frac{1}{2}\left\{E U_{3}(e e-p d)+\left[\frac{1}{2} E U_{3}(e e-c d)+\frac{1}{4}\left\{\frac{E U_{3}(e i-c d)+E U_{3}(i e-c d)}{2}\right\}+\frac{1}{4} E U_{3}(i i-c d)\right]\right\}, s=3,
\end{aligned}
$$


while in version 2 , it is

$$
\begin{aligned}
& \frac{1}{2}\left\{E U_{1}(e e-p d)+\left[\frac{1}{2} E U_{1}(e e-c d)+\frac{3}{8}\left\{\frac{E U_{1}(e i-n d)+E U_{1}(i e-n d)}{2}\right\}+\frac{1}{8} E U_{1}(i i-n d)\right]\right\}, s=1, \\
& \frac{1}{2}\left\{E U_{2}(e e-p d)+\left[\frac{1}{2} E U_{2}(e e-c d)+\frac{3}{8}\left\{\frac{E U_{2}(e i-n d)+E U_{2}(i e-n d)}{2}\right\}+\frac{1}{8} E U_{2}(i i-c d)\right]\right\}, s=2, \\
& \frac{1}{2}\left\{E U_{3}(e e-p d)+\left[\frac{1}{2} E U_{3}(e e-c d)+\frac{3}{8}\left\{\frac{E U_{3}(e i-p d)+E U_{3}(i e-p d)}{2}\right\}+\frac{1}{8} E U_{3}(i i-c d)\right]\right\}, s=3 .
\end{aligned}
$$

It turns out that, if the depositors are weakly risk averse, ND in period 1 produces the highest value for the government's welfare criterion, followed by PD and then CD. However, CD is the banks' preferred choice in period 1, followed by PD and then ND. So the government must rule out both $\mathrm{CD}$ and $\mathrm{PD}$, imposing ND, which is to say, prohibiting diversification.

If the depositors are moderately or strongly risk averse, $\mathrm{PD}$ in period 1 produces the highest value for the government's welfare criterion, followed by CD and then ND. Again, however, the banks prefer CD in period 1, followed by PD and then ND. So the government must prohibit CD in period 1, causing to banks to choose PD. That is, the government limits but does not prohibit diversification. 